\title{
Sex Differences in the Association between Night Shift Work and the Risk of Cancers: A Meta-Analysis of 57 Articles
}

\author{
Wen Liu $\left(\mathbb{D}\right.$, Zhonghan Zhou $\left(\mathbb{D}\right.$, Dahai Dong $\mathbb{D}$, Lijiang Sun $\mathbb{D}^{\mathbb{D}}$, and Guiming Zhang $\mathbb{D}$ \\ Department of Urology, The Affiliated Hospital of Qingdao University, Qingdao, China \\ Correspondence should be addressed to Lijiang Sun; slijiang999@126.com and Guiming Zhang; zhangguiming9@126.com
}

Received 10 July 2018; Accepted 25 September 2018; Published 26 November 2018

Academic Editor: Fabrizia Bamonti

Copyright @ 2018 Wen Liu et al. This is an open access article distributed under the Creative Commons Attribution License, which permits unrestricted use, distribution, and reproduction in any medium, provided the original work is properly cited.

\begin{abstract}
Objectives. To identify the association between night shift work and the risk of various cancers with a comprehensive perspective and to explore sex differences in this association. Methods. We searched PubMed, Embase, and Web of Science for studies on the effect of night shift work on cancer, including case-control, cohort, and nested case-control studies. We computed risk estimates with 95\% confidence intervals (CIs) in a random or fixed effects model and quantified heterogeneity using the $I^{2}$ statistic. Subgroup, metaregression, and sensitivity analyses were performed to explore potential sources of heterogeneity. Contour-enhanced funnel plots and the trim and fill method were used together to analyze bias. Linear dose-response analysis was used to quantitatively estimate the accumulative effect of night shift work on the risk of cancer. Results. Fifty-eight studies were eligible for our meta-analysis, including 5,143,838 participants. In the random effects model, the pooled odds ratio (OR) of cancers was $1.15\left(95 \% \mathrm{CI}=1.08-1.22, P<0.001 ; I^{2}=76.2 \%\right)$. Night shift work increased the cancer risk in both men $(\mathrm{OR}=1.14$, $95 \% \mathrm{CI}=1.05-1.25, P=0.003)$ and women $(\mathrm{OR}=1.12,95 \% \mathrm{CI}=1.04-1.20, P=0.002)$. Subgroup analyses showed that night shift work positively increased the risk of breast $(\mathrm{OR}=1.22,95 \% \mathrm{CI}=1.08-1.38)$, prostate $(\mathrm{OR}=1.26,95 \% \mathrm{CI}=1.05-1.52)$, and digestive system $(\mathrm{OR}=1.15,95 \% \mathrm{CI}=1.01-1.32)$ cancers. For every 5 years of night shift work, the cancer risk increased by $3.2 \%(\mathrm{OR}=1.032,95 \% \mathrm{CI}=1.013-1.051)$. Conclusion. This is the first meta-analysis identifying the positive association between night shift work and the risk of cancer and verifying that there is no sex difference in the effect of night shift work on cancer risk. Cancer risk increases with cumulative years of night shift work.
\end{abstract}

\section{Introduction}

Recent years have witnessed a rise in the number of people working late or night shifts in different employment sectors, such as healthcare, construction, transportation, and food preparation $[1,2]$. The rate of shift work can exceed $15 \%$ of the workforce in many countries of North America, continental Europe, and Australia [2], and the trend is increasing. Night shift workers not only have higher short-term safety risks because of decreased alertness [3] but also have greater long-term health risks, including for diabetes [4], obesity [5], cardiovascular disease [6], depression [7], and cancer [8]. In 2007, a report by the International Agency for Research on Cancer (IARC) classified night shift work involving circadian disruption as "probably carcinogenic to humans" based on sufficient evidence in animal experiment and limited evidence in humans [9]. Therefore, investigating the influence of night shift work has captured attention. Most previous original studies verified the effect of night shift work on cancer risk, but the results are controversial for different cancers. Some findings have indicated that night shift work is significantly associated with higher cancer risk [10-39] whereas other studies have provided insignificant evidence for this relationship [40-66], motivating further study.

There were several postulated causal mechanisms that explain how night shift work multiplies cancer risk. First, melatonin, a marker of circadian rhythms, has a fundamental impact on inhibiting carcinogenesis through antioxidation, regulation of immunity, free radical scavenging, and antiangiogenesis [67]. Generally, night shift workers have a substantially decreased melatonin level during the nighttime $[68,69]$. Melatonin suppression has been reported in breast [69], prostate [70], lung [71], ovarian [67], and gastrointestinal [72] cancers. Second, the 24-hour circadian rhythm 
is generated via interacting feedback loops of the circadian genes in all cells of both the hypothalamic suprachiasmatic nucleus (SCN) and all peripheral tissues $[73,74]$. Night shift work can induce a conflict between the endogenous circadian clock and the external shifted sleep period and feeding behavior, leading to a dampening of the gene expression rhythm (25\% of circadian genes) and subsequent disordered expression of transcription and translation in these cells $[73,74]$. These disturbances can interfere with cell proliferation, apoptosis, hormonal balancing, metabolism, DNA damage repair, and immune and neuroendocrine functions. Recent studies have uncovered that the disruptive expression of circadian genes especially increases the risk of cancers in the immune, skeletal, digestive, and reproductive systems in which cell proliferation, metabolism, and DNA damage repair are required to maintain daily function [74]. Overall, the mechanisms based on hormonal and molecular levels manifest that the influence of night shift work on cancer is systemic and is not limited to a specific organ. However, many previous meta-analyses have identified the association of night shift work with only one type of cancer, including breast [75-78], prostate [79-81], and colorectal [82] cancers, among others. Only one study [8] analyzed the relationship between night shift work and the risk of cancers in women. Accordingly, we aimed to classify the association between night shift work and the risk of multiple cancers from a comprehensive perspective.

Previous studies have revealed that the circadian timing system differs in the sexes, which is mediated by different neuroendocrine contexts, such as sex hormones and their receptors in SCN $[16,83,84]$. Compared with male sex, female sex has been associated with earlier timing and larger amplitude of melatonin and earlier timing and longer duration of sleep $[85,86]$. After night shift work, women showed greater impaired performance in health and cognition compared with men. For example, accuracy, alertness, the amplitude of melatonin, and working memory deteriorate more in women $[3,86,87]$, enabling us to understand why female was more susceptible to sleep and wake disturbances after shift work [3]. More intense response to shift work in women reminds us whether the effect of night shift work on cancers varies with different genders.

Consequently, we conducted a meta-analysis to investigate this sex difference. We also expanded upon previous meta-analyses by not only evaluating the association between night shift work and a specific cancer but also estimating whether there was a dose-response relationship between night shift work and the risk of multiple cancers.

\section{Methods}

2.1. Search Strategy. We conducted a comprehensive updated search through May 2018 using PubMed, Embase, and Web of Science databases. Two investigators searched for eligible English articles independently. The search terms were "night shift work" or "rotating shift work" or "night work" or "shift work" and "carcinoma" or "neoplasm" or "tumor" or "cancer". In addition, we manually reviewed the reference lists of articles for additional relevant studies.
2.2. Inclusion and Exclusion Criteria. Studies were included if they satisfied the following criteria: (i) the research was a case-control study, cohort study, or nested case-control study; (ii) the exposure of interest was night shift work, and the outcome of interest was the risk of any type of cancer; (iii) the study reported adjusted risk estimates (odds ratio, OR; relative risk, RR; hazard ratio, HR) with 95\% confidence intervals (CIs) or provided sufficient data to allow calculation. Studies were excluded if they satisfied the following criteria: (i) the study did not provide sufficient data; (ii) the study mentioned recurrent cancer; (iii) when more than one article was based on the same study population, we only included the study with the largest number of cases.

2.3. Data Extraction. Data extraction was conducted independently by two authors for the following items: first author, publication year, study location, study design, number of cases, occupation, quality score, definition of exposure, participant sex, type of cancer, adjusted OR with 95\% CI, adjusted covariates, and exposure assessment. As the prevalence of tumor is very low, we considered that ORs equaled RRs or HRs, providing similar risk estimates [88]. According to the definition of work schedule, we divided work schedules into rotating shift (working a regular shift schedule), fixed shift (permanent night work), and mixed (with no clear work schedule). ORs of the longest versus shortest exposure time were extracted from articles as the exposure indicator for statistical analysis. We also extracted dose information from ordinal categorical data ( $\geq 3$ levels of the exposure category) for dose-response meta-analysis.

2.4. Quality Assessment. Two authors performed quality assessment using the Newcastle-Ottawa Quality Assessment Scale (NOS) [89]. The scale comprises a total of 9 points on the three parts of the NOS, including participant selection (0-4 points), comparability (0-2 points), and exposure or outcome assessment ( $0-3$ points). Scores of $\geq 7$ indicate a high quality.

2.5. Statistical Analysis. All statistical analyses were performed using Stata version 12.0 (StataCorp, College Station, TX, USA). We preferentially extracted adjusted ORs from original articles to evaluate the association between night shift work and cancer risk. If there were no adjusted ORs for specific subgroup analyses, a number of cases and participants would be extracted to calculate OR. The inverse variance method was used to combine ORs. If $I^{2}$ for the heterogeneity test was $\leq 50 \%$, a fixed effects model was adopted to pool ORs; otherwise, a random effects model was selected. To explore potential heterogeneity, we performed subgroup analyses, metaregression analyses, and sensitivity analyses. One subgroup analysis was the classification of work schedules; we used a random effects model to evaluate the effect size for cancer on different work schedules [80]. To confirm the stability of results, a sensitivity analysis was conducted by omitting one study and then recalculating the rest of studies. The leave-one-out analysis was used to examine the weight of influence of each study on pooled OR [90]. 


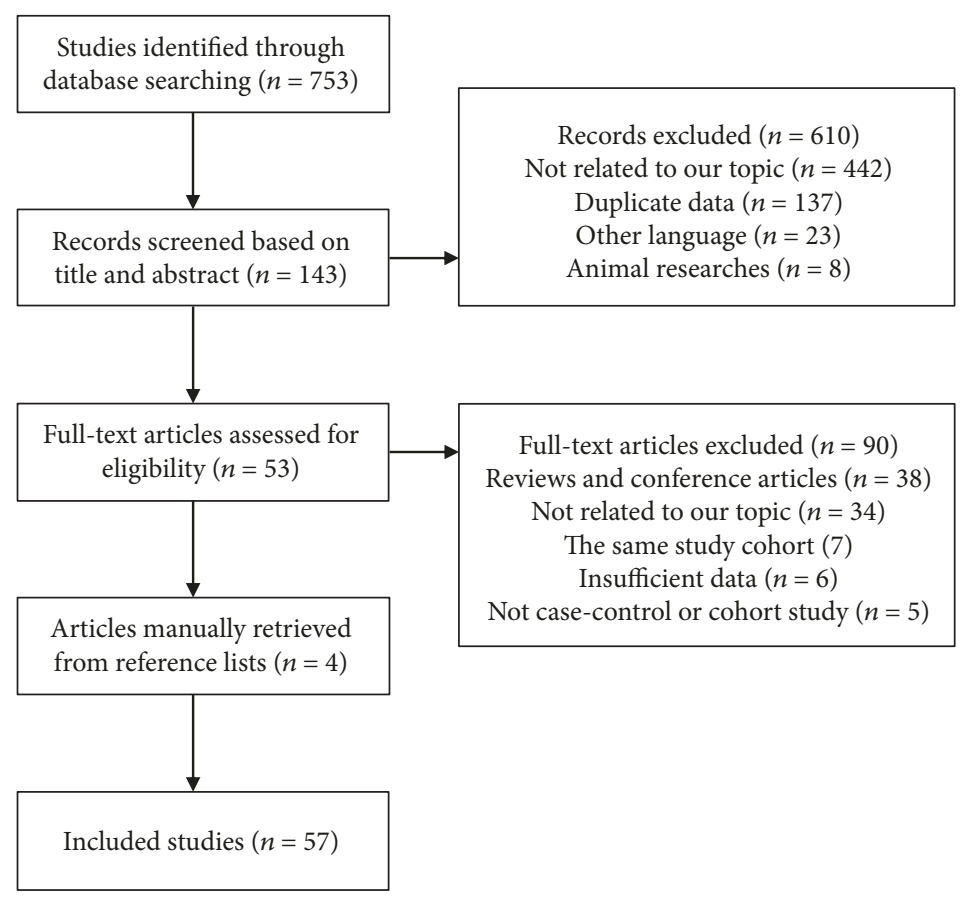

FIgURE 1: Flow chart of identification of relevant studies.

A generalized least-squares trend (GLST) model was used to estimate the overall dose-response relationship of night shift work and the risk of cancer by computing risk estimates for different ordinal levels of night shift work. There were at least three ordinal levels of the exposure category in each study. The midpoint of the upper and lower boundaries of each level was considered the average exposure. The upper boundary of the highest level was considered the same as the adjacent category if it was not provided [76]. We used a twostage random effect model to evaluate the linearity between night shift work and the risk of cancer.

Potential publication bias was estimated with the Begg funnel plot. Furthermore, the contour-enhanced funnel plot and the trim and fill method were used together to analyze the cause of bias. All reported $P$ values were two-sided, and statistical significance was set at $P \leq 0.05$.

\section{Results}

3.1. Study Selection. Figure 1 illustrates the results of the literature search and the process of selection. A total of 753 articles were initially identified from PubMed, Embase, and Web of Science databases. After screening based on the title and abstract, 143 articles were selected for full-text assessment; 53 studies were eligible for the final analysis. We also retrieved four relevant articles from the reference lists. Finally, 57 studies [10-66] were included in the analysis of the association of night shift work with risk of cancer.

3.2. Study Characteristics. The characteristics of the abovementioned studies are summarized in Table 1. Fifty-seven articles were included in this meta-analysis, including 21 case-control studies, 6 nested case-control studies, and 30 cohort studies. One article [10] included two cohorts, the
Nurses' Health Study (NHS) and Nurses' Health Study II (NHS II). Therefore, a total of 58 studies were finally enrolled, involving 225,976 cases and 5,143,838 participants. We extracted information about sex in each article, except these articles that did not include classification by sex $[12,15,48]$, to analyze the effect of night shift work on cancers in men and women separately. Several studies [20, 28, 43, 44, 53] analyzed the association between night shift work and different kinds of cancers. We also classified all kinds of cancer analyzed in the included studies into seven categories, including digestive system, hematological system, prostate, breast, reproductive system, lung, and skin cancers. A total 27 articles were from Europe, 11 from Asia, 17 from North America, and 3 from Australia. Most studies were based on a population with no specific occupation whereas other studies involved participants with a specific occupation, such as nurses, textile workers, women in the military, and pilots. According to the definition of night shift work, work schedules were classified as rotating shift (29 studies), fixed shift (9 studies), or mixed shift (27 studies). In fact, a cross section of studies described different work schedules, which we extracted simultaneously. Exposure assessment was performed using a questionnaire, interview, or databases. A total 43 studies were adjusted for more than four confounders and 15 studies for fewer than four confounders. The average NOS score was 7.2, and scores ranged from 4 to 8 .

3.3. Association between Night Shift Work and the Risk of Various Cancers. The random effects model was used to pool the ORs, indicating the relationship between night shift work and risk of multiple cancers. The pooled OR was 1.15 (95\% CI $=1.08-1.22, P<0.001)$, with high heterogeneity $\left(I^{2}=76.2 \%, P \leq 0.001\right)$ (shown in online Figure $\left.\mathrm{S} 1\right)$. We 


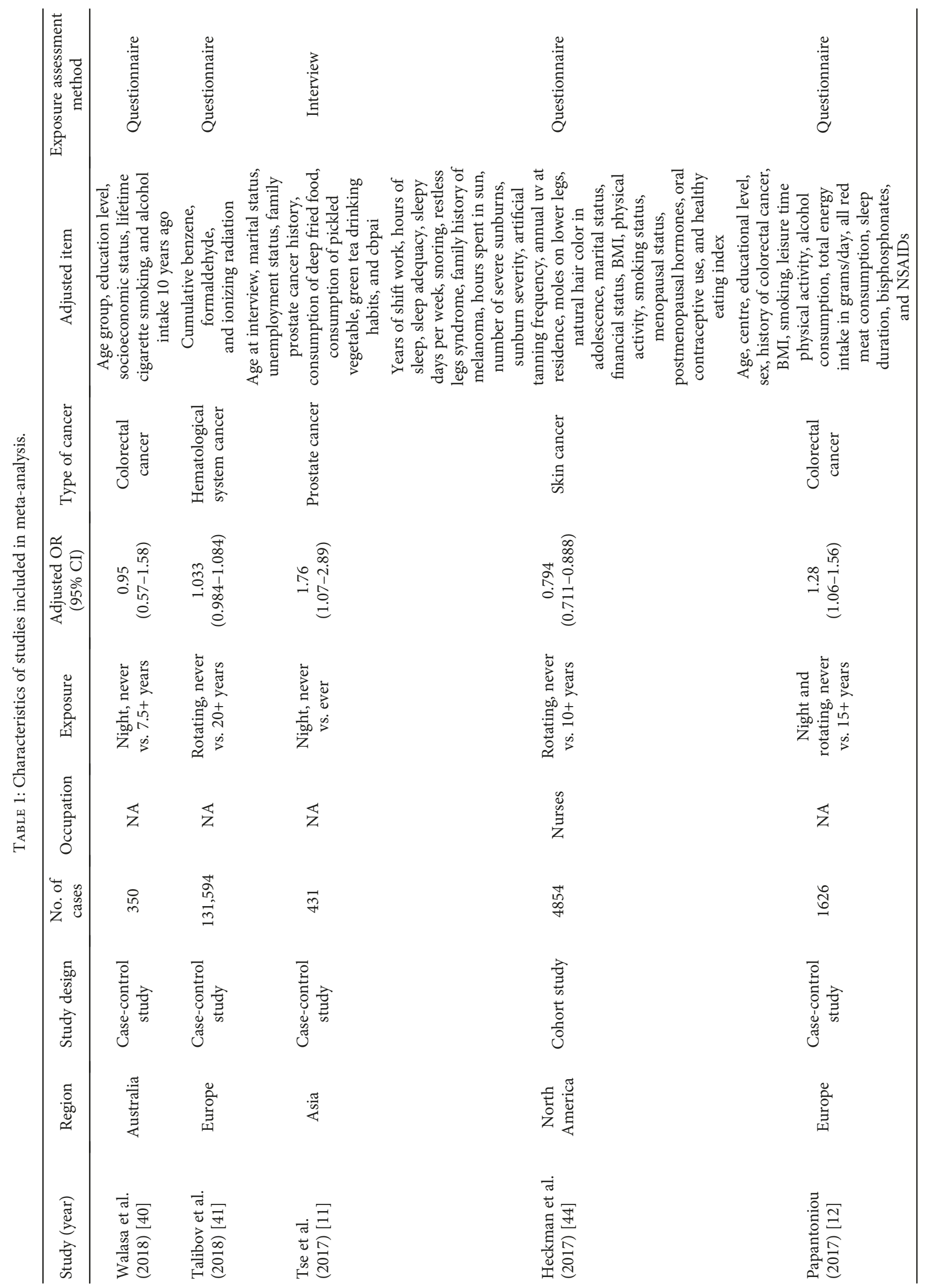




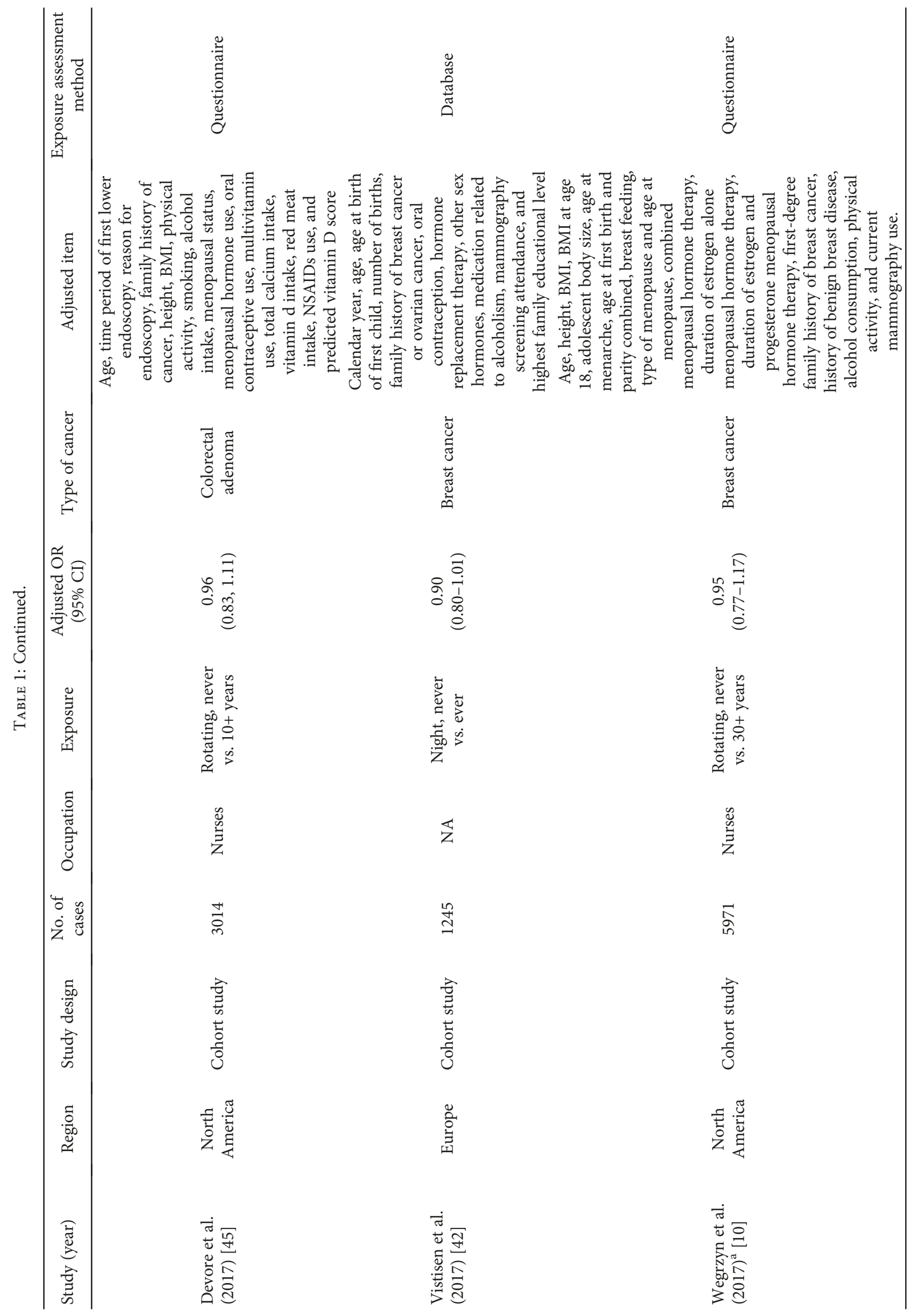




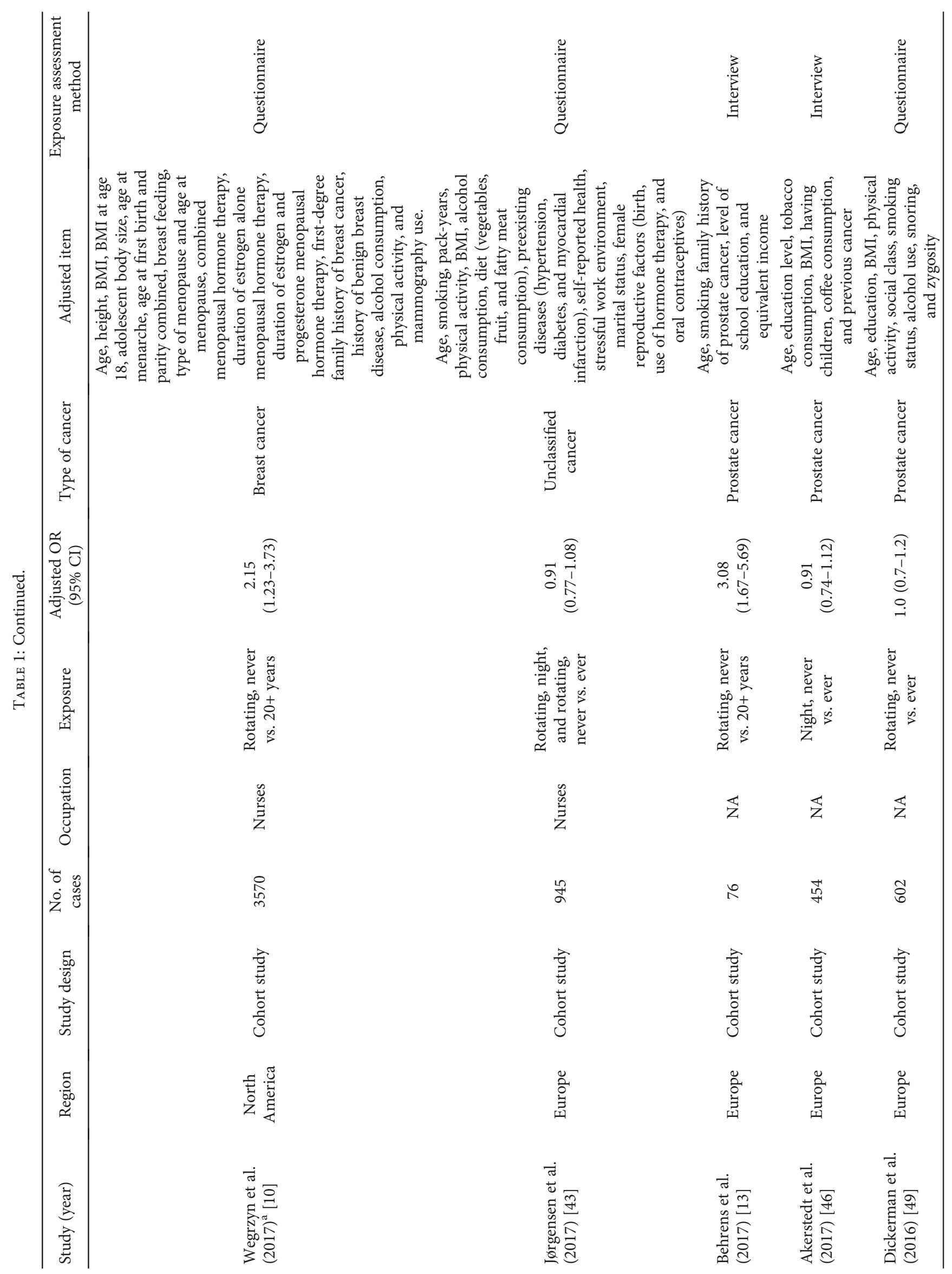




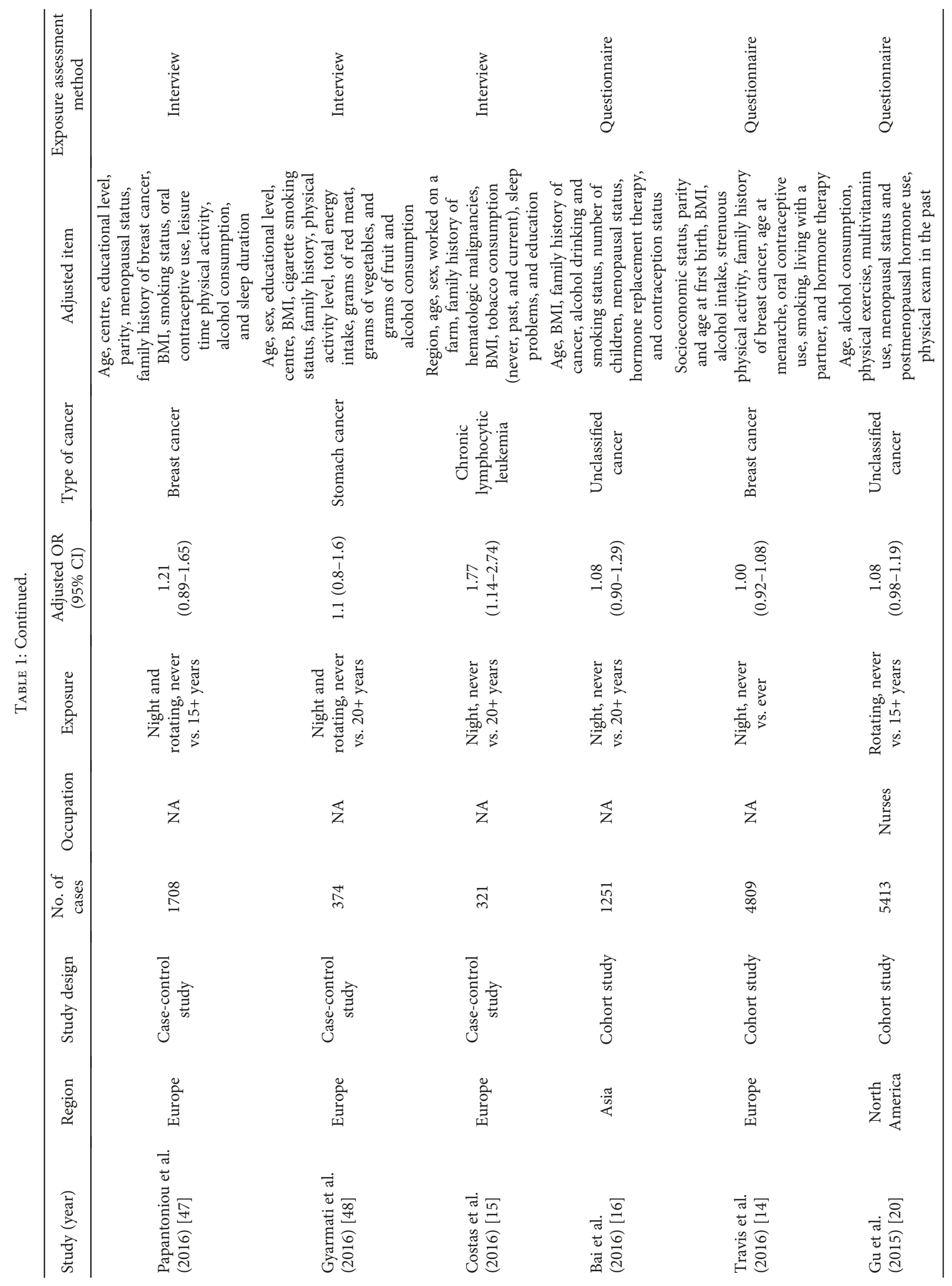




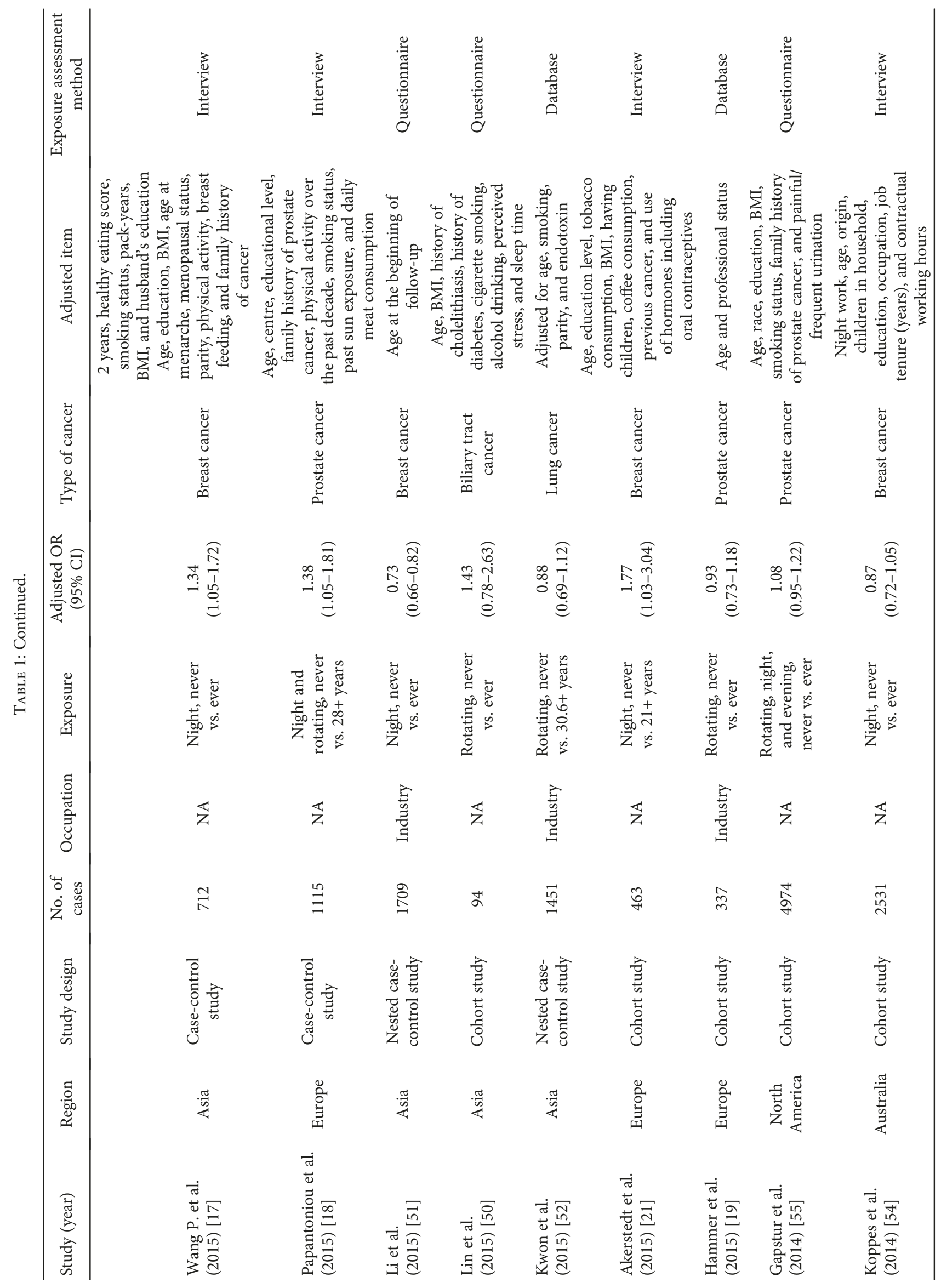




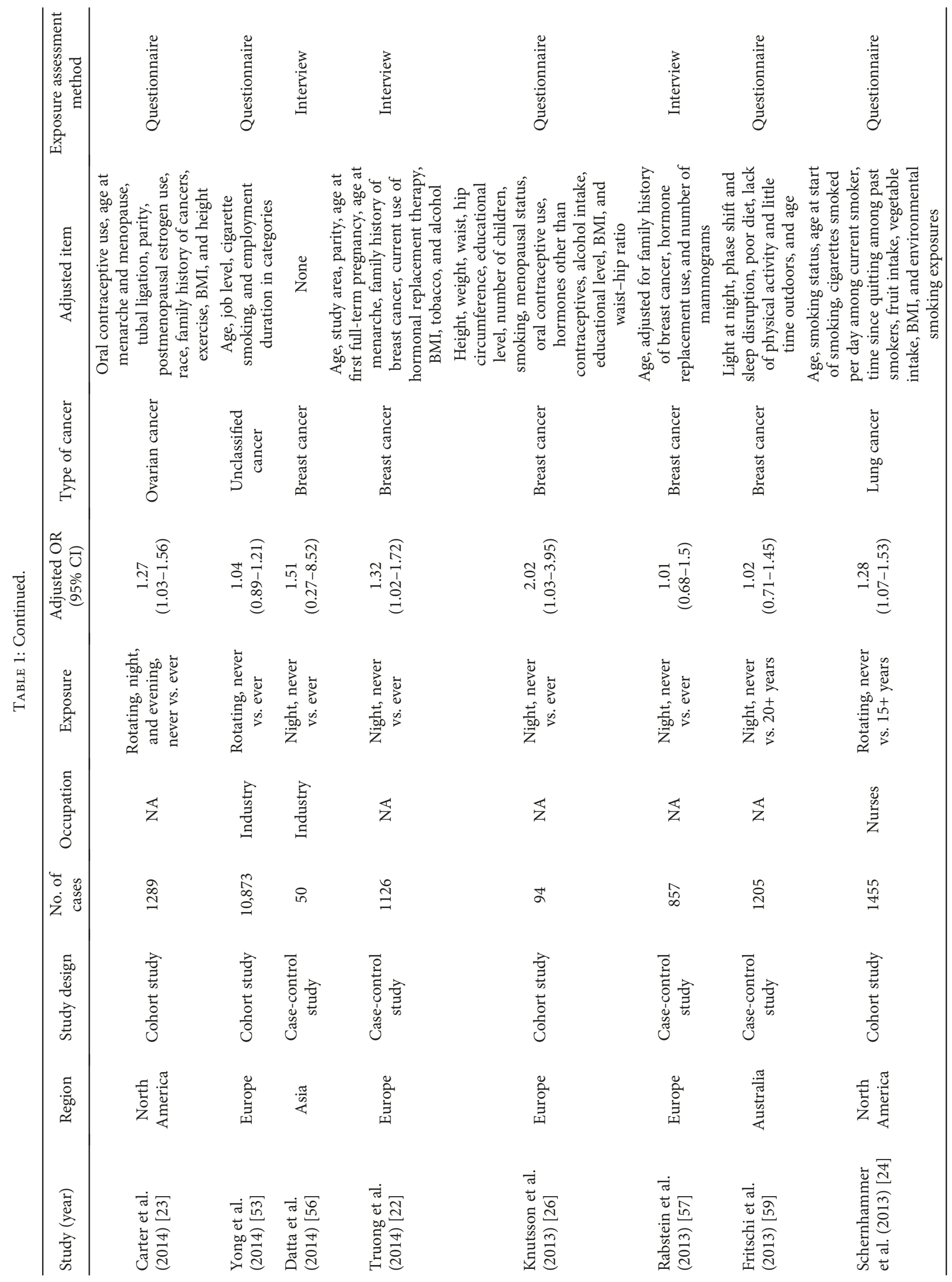




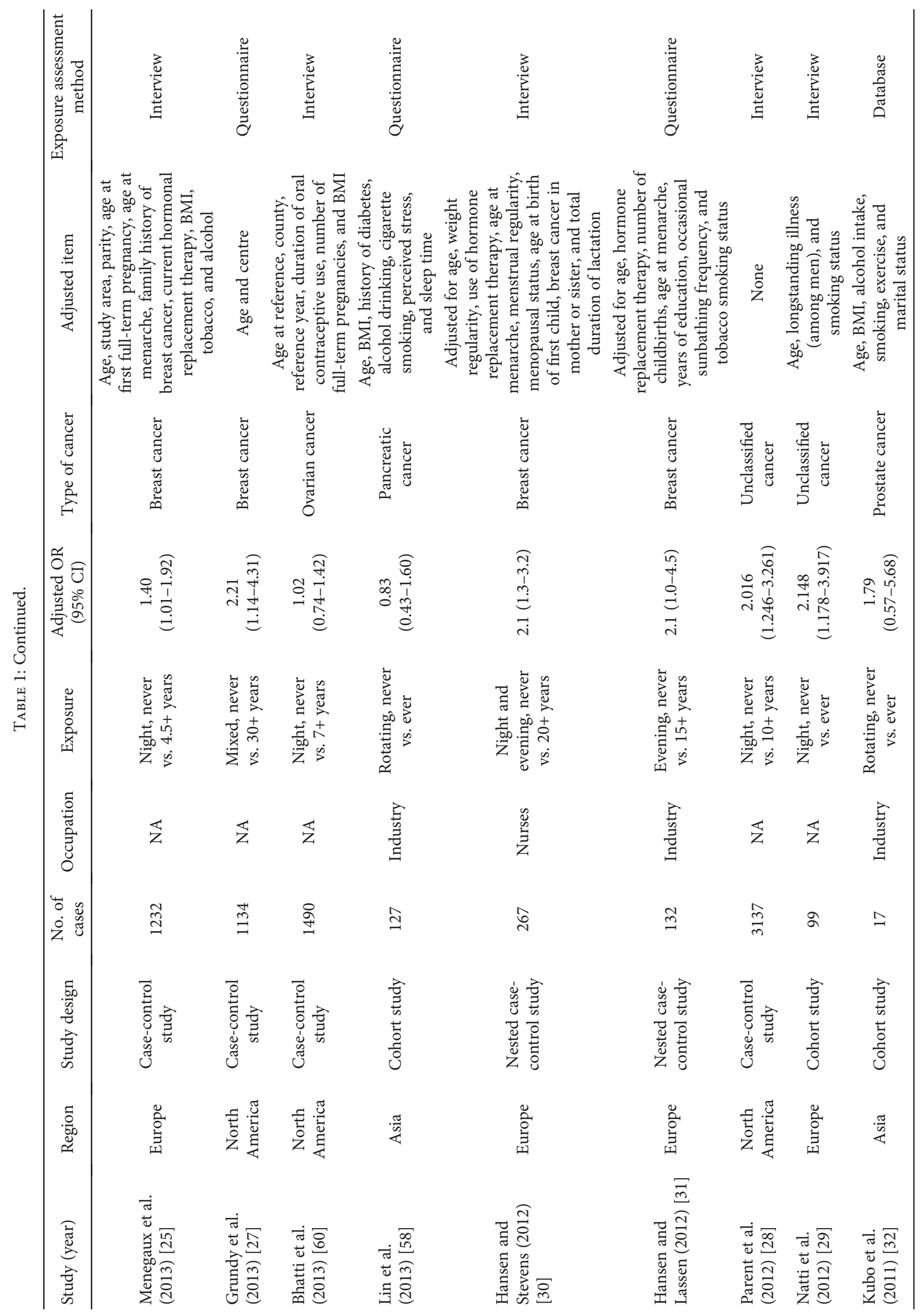




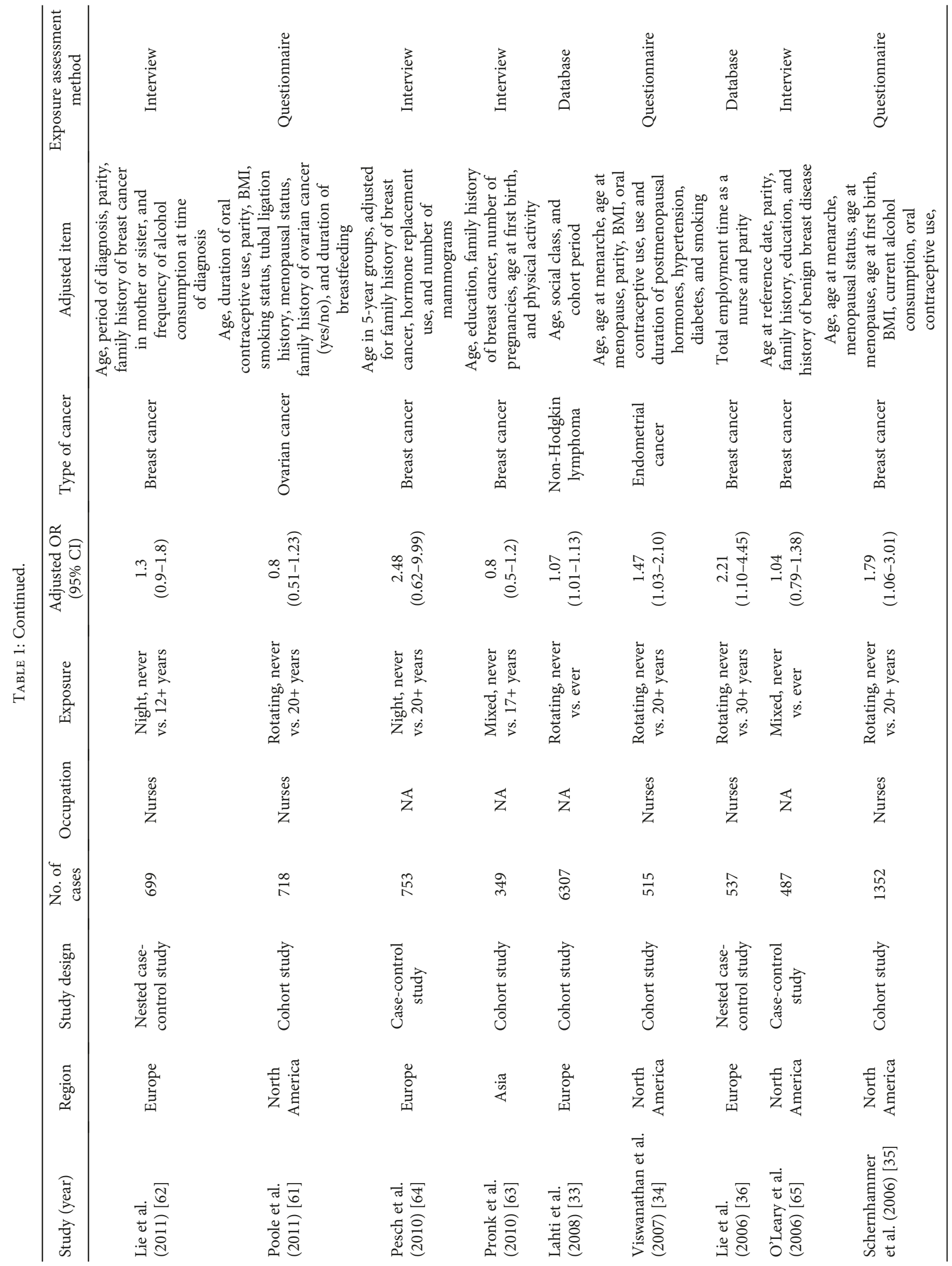




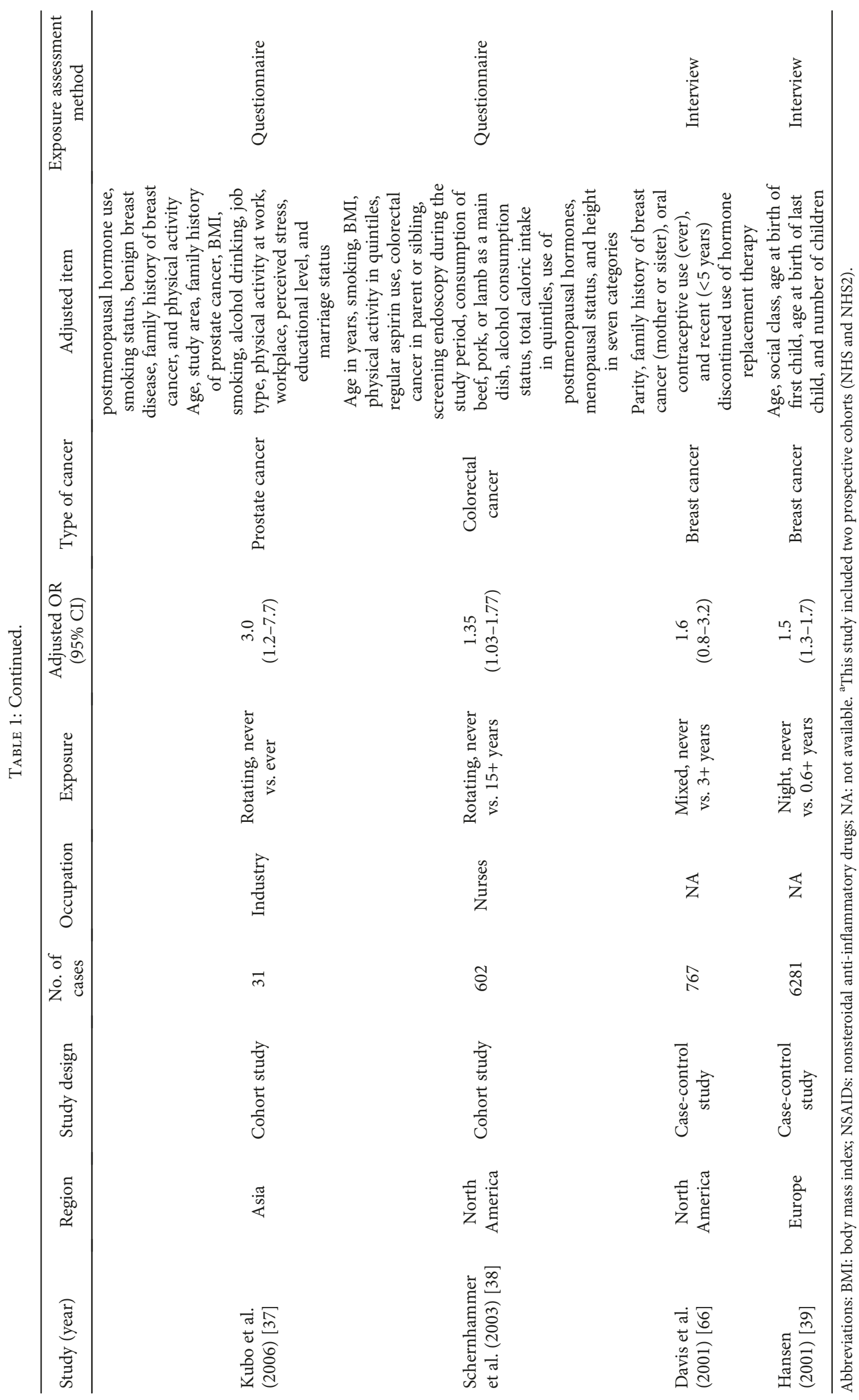


observed that night shift work could increase the risk of cancers both in men $(\mathrm{OR}=1.14,95 \% \mathrm{CI}=1.05-1.25, P=$ $0.003)$ and women $(\mathrm{OR}=1.12,95 \% \mathrm{CI}=1.04-1.20, P=0.002$ ), with high heterogeneity in men $\left(I^{2}=78.3 \%, P \leq 0.001\right)$ and women $\left(I^{2}=62.3 \%, P \leq 0.001\right)$ (Figure 2$)$. In cancers that can occur in both men and women (i.e., excluding breast, prostate, and reproductive system cancers, such as ovarian, endometrial, and testis cancer), night shift work demonstrated a positive association with the risk of cancer in men $(\mathrm{OR}=1.09,95 \% \mathrm{CI}=1.01-1.17, P=0.031)$ but not in women $(\mathrm{OR}=1.02,95 \% \mathrm{CI}=0.94-1.12, P=0.637)$.

3.4. Subgroup Analysis and Metaregression Analysis. To explore the source of potential heterogeneity and assess the influence of specific characteristics of night shift work and cancer risk, we conducted subgroup analyses, including for shift schedule, type of cancer, study region, participant occupation, study design, exposure assessment, number of adjusted variables, and NOS score (Table 2). Among the different work schedules, rotating shift work $(\mathrm{OR}=1.14,95 \%$ $\mathrm{CI}=1.04-1.24)$ increased cancer risk whereas fixed shift work $(\mathrm{OR}=1.09,95 \% \mathrm{CI}=0.90-1.31)$ did not. A significant relationship was observed for breast cancer $(\mathrm{OR}=1.22,95 \%$ $\mathrm{CI}=1.08-1.38)$, prostate cancer $(\mathrm{OR}=1.26,95 \% \mathrm{CI}=1.05-$ $1.52)$, and digestive system cancer $(\mathrm{OR}=1.15,95 \%$ $\mathrm{CI}=1.01-1.32)$. With respect to region, studies in Europe $(\mathrm{OR}=1.18,95 \% \mathrm{CI}=1.10-1.28)$ and North America $(\mathrm{OR}=1.16,95 \% \mathrm{CI}=1.04-1.31)$ showed higher ORs than those in Asia and Australia. When stratified by study design, a positive association was revealed for casecontrol studies $(\mathrm{OR}=1.28,95 \% \mathrm{CI}=1.15-1.42)$ and cohort studies $(\mathrm{OR}=1.07,95 \% \mathrm{CI}=1.00-1.15)$ but not nested case-control studies. For different occupations, studies based on populations in which no specific occupation was classified showed higher risk estimates (OR $=1.17,95 \%$ $\mathrm{CI}=1.10-1.25)$. Nurses $(\mathrm{OR}=1.17,95 \% \mathrm{CI}=1.02-1.35)$ had elevated cancer risk, but participants with industrial occupations did not. The interview group, which had more comprehensive information collection, presented a higher risk estimate $(\mathrm{OR}=1.32,95 \% \mathrm{CI}=1.17-1.49)$ than studies using questionnaires and databases to collect information. Regarding NOS score, studies with high-quality scores were associated with increased risk $(\mathrm{OR}=1.14,95 \% \mathrm{CI}=1.08-$ $1.21)$ and decreased heterogeneity $\left(I^{2}=61.6 \%, P \leq 0.001\right)$ whereas those with low-quality scores did not show this positive relationship and had high heterogeneity $\left(I^{2}=86.9 \%\right.$, $P \leq 0.001)$. Additionally, increased risk was present in studies with more than four adjusted variables. Studies with fewer than four adjusted variables showed no elevated risk of cancer, with high heterogeneity $\left(I^{2}=82.7 \%, P \leq\right.$ $0.001)$. We performed metaregression analyses to assess the potential heterogeneity sources (Table 2); however, the results showed that none of the subgroups generated the potential heterogeneity.

3.5. Sensitivity Analysis. Sensitivity analysis showed that the pooled ORs were stable and did not identify the origins of heterogeneity. After omitting 19 studies by the leave-oneout analyses, we found a stable positive relationship
$(\mathrm{OR}=1.06,95 \% \mathrm{CI}=1.02-1.11)$ between night shift work and the risk of cancer, with low heterogeneity $\left(I^{2}=29.8 \%\right)$. It was found that none of the individual studies could powerfully change the positive result.

3.6. Dose-Response Analysis of Night Shift Work and the Risk of Cancers. Twenty-nine studies, which involved at least three levels of night shift exposure, were included in the doseresponse analysis of night shift work and cancer risk. We used the two-stage random effects model to evaluate the linearity relationship $(P<0.001)$. For every 5 years of night shift work, the risk of cancer increased by $3.2 \%(\mathrm{OR}=1.032,95 \%$ $\mathrm{CI}=1.013-1.051)$ (Figure 3).

3.7. Publication Bias. The Begg test showed a potential publication bias among all enrolled studies $(P=0.001)$. After combining the trim and fill method and contour-enhanced funnel plot, the result showed that most of the filled studies were outside the $10 \%$ line, which indicated that the previously verified bias was mostly caused by the high heterogeneity, not the publication bias (Figure 4). The filled risk estimate was still positive, as before $(\mathrm{OR}=1.06,95 \% \mathrm{CI}=1.01-1.11)$, such that the pooled OR was stable in our study.

\section{Discussion}

This meta-analysis, consisting of 58 studies with 225,976 cases and 5,143,838 participants, revealed a positive relationship between night shift work and the risk of cancer. Compared with people who never experience working late, the risk of cancer was found to be increased by $15 \%$ in all shift workers, by $12 \%$ in female workers and $14 \%$ in male workers. A linear dose-response relationship showed a positive gradient of cancer risk with cumulative years of night shift work; for every 5 years of night shift work, cancer risk increased by $3.2 \%$. Yuan et al. [8] confirmed that night shift work elevates the risk of multiple cancers in women, especially breast cancer. Several meta-analyses [79-81] have verified the positive relationship between night shift work and risk of prostate cancer. We obtained the same result, i.e., that long-time night shift work was associated with a higher risk of breast cancer $(\mathrm{OR}=1.22,95 \% \mathrm{CI}=1.08-1.38)$, prostate cancer $(\mathrm{OR}=1.26$, $95 \% \mathrm{CI}=1.05-1.52)$, and cancers in women $(\mathrm{OR}=1.12$, 95\% CI $=1.04-1.20)$. As far as we know, this is the first meta-analysis to comprehensively explore the effect of night shift work on multiple cancers in the whole population and separately in men and women.

Tissue-specific functions and output circadian rhythms are related to the different cell-based clock genes in periphery [83]. To exclude the tissue-specific influence, we only analyzed cancers that can occur in both men and women and found that night shift work increased cancer risk in men $(\mathrm{OR}=1.09,95 \% \mathrm{CI}=1.02-1.17)$ but not in women $(\mathrm{OR}=1.02,95 \% \mathrm{CI}=0.94-1.12)$. One meta-analysis involving colorectal cancer [82] demonstrated that night shift work could increase the risk of this type of cancer in women. However, we did not find a risk relationship for either men or women based on more studies of colorectal cancer (data not shown). Although there were considerably fewer articles 


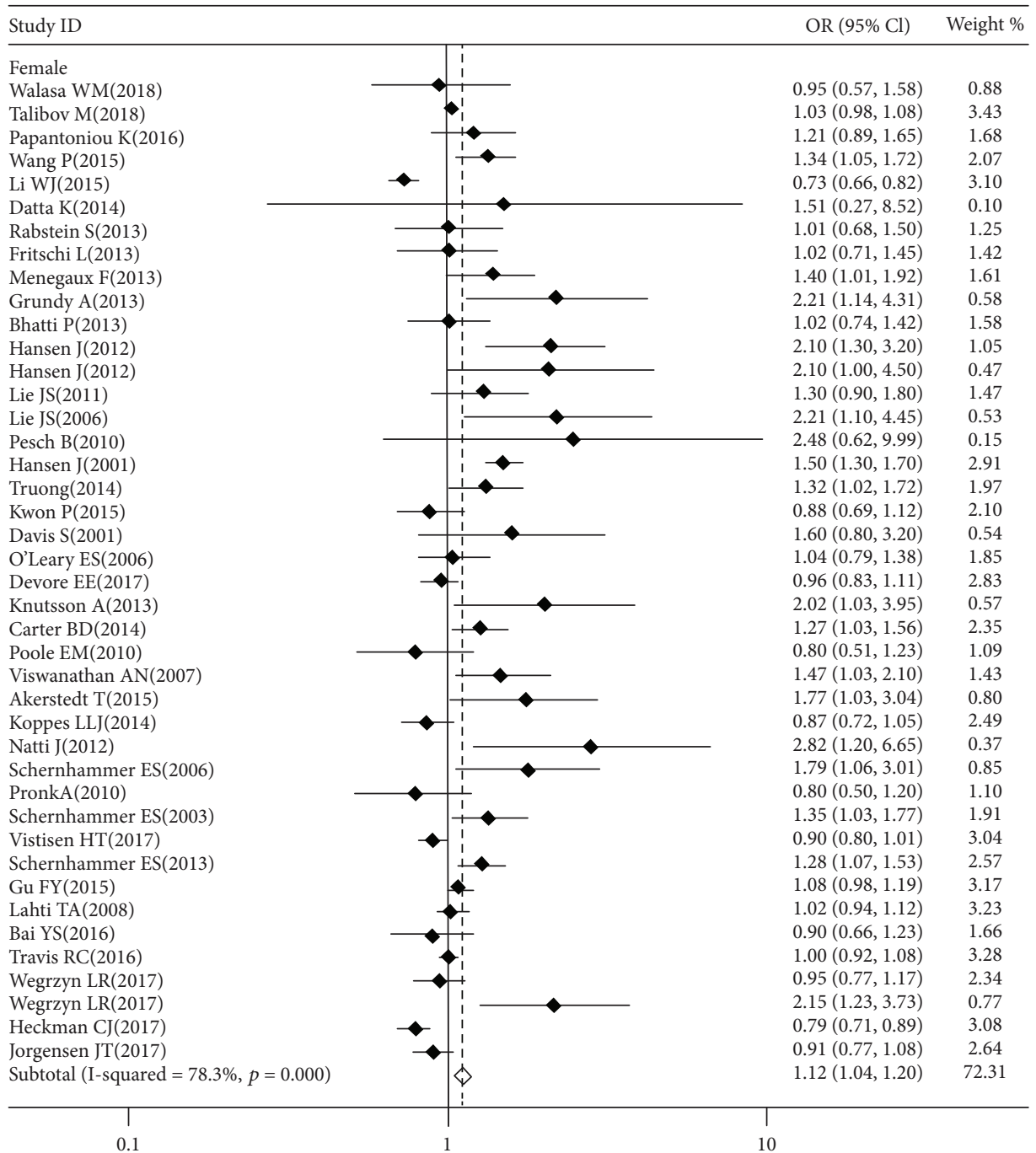

(a)

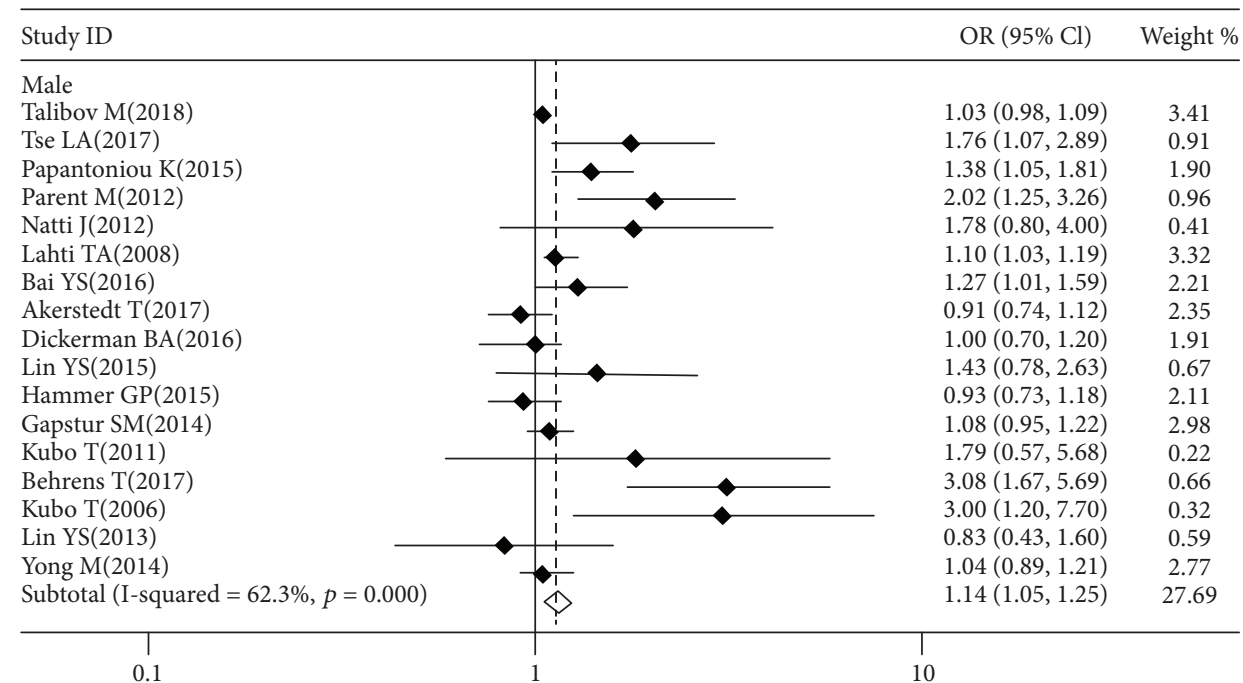

(b)

FIGURE 2: Forest plots of studies describing the association between night shift work and the risk of multiple cancers in women (a) and men (b) separately. $I^{2}$ : the indicator for judging the degree of heterogeneity; OR: odds ratio; CI: confidence interval. The squares and horizontal lines represent the study-specific OR and $95 \%$ CI. The diamond represents the pooled OR and 95\% CI. 
TABLE 2: The results of subgroup analyses and metaregression analyses on the association between night shift work and the risk of cancers.

\begin{tabular}{|c|c|c|c|c|c|c|}
\hline Subgroup & No. of studies & Weight (\%) & OR $(95 \% \mathrm{CI})$ & $I^{2}$ & $P$ for heterogeneity & $P^{*}$ for interaction \\
\hline Shift schedule ${ }^{a}$ & & & & & & 0.570 \\
\hline Rotating shift & 29 & 46.97 & $1.14(1.04-1.24)$ & $68.7 \%$ & $<0.001$ & \\
\hline Fixed shift & 9 & 11.19 & $1.09(0.90-1.31)$ & $51.1 \%$ & 0.037 & \\
\hline Mixed shift & 27 & 41.84 & $1.20(0.82-1.77)$ & $80.7 \%$ & $<0.001$ & \\
\hline Type of cancer ${ }^{b}$ & & & & & & 0.298 \\
\hline Digestive system cancer & 11 & 15.72 & $1.15(1.01-1.32)$ & $40.2 \%$ & 0.081 & \\
\hline Hematological system cancer & 5 & 9.12 & $1.08(0.99-1.17)$ & $54.7 \%$ & 0.066 & \\
\hline Prostate cancer & 11 & 16.10 & $1.26(1.05-1.52)$ & $73.2 \%$ & $<0.001$ & \\
\hline Breast cancer & 37 & 39.62 & $1.22(1.08-1.38)$ & $81.2 \%$ & $<0.001$ & \\
\hline Reproductive system cancer & 6 & 7.99 & $1.06(0.85-1.32)$ & $49.5 \%$ & 0.078 & \\
\hline Lung cancer & 5 & 7.53 & $1.08(0.87-1.35)$ & $53.4 \%$ & 0.073 & \\
\hline Skin cancer & 3 & 3.92 & $0.93(0.50-1.74)$ & $74.9 \%$ & 0.019 & \\
\hline Region & & & & & & 0.298 \\
\hline Australia & 3 & 5.03 & $0.91(0.77-1.06)$ & $0.0 \%$ & 0.728 & \\
\hline Europe & 27 & 48.92 & $1.18(1.10-1.28)$ & $75.1 \%$ & $<0.001$ & \\
\hline Asia & 11 & 14.29 & $1.11(0.88-1.39)$ & $78.3 \%$ & $<0.001$ & \\
\hline North America & 17 & 31.75 & $1.16(1.04-1.31)$ & $76.1 \%$ & $<0.001$ & \\
\hline Occupation & & & & & & 0.795 \\
\hline Unclassified occupation & 35 & 61.45 & $1.17(1.10-1.25)$ & $69.7 \%$ & $<0.001$ & \\
\hline Industry & 9 & 12.09 & $1.00(0.81-1.24)$ & $72.8 \%$ & $<0.001$ & \\
\hline Nurses & 14 & 26.46 & $1.17(1.02-1.35)$ & $80.6 \%$ & $<0.001$ & \\
\hline Study design & & & & & & 0.845 \\
\hline Case-control study & 21 & 32.23 & $1.28(1.15-1.42)$ & $66.5 \%$ & $<0.001$ & \\
\hline Nested case-control study & 6 & 9.08 & $1.30(0.89-1.90)$ & $88.0 \%$ & $<0.001$ & \\
\hline Cohort study & 31 & 58.69 & $1.07(1.00-1.15)$ & $70.9 \%$ & $<0.001$ & \\
\hline Exposure assessment & & & & & & 0.075 \\
\hline Questionnaire & 28 & 53.99 & $1.08(1.00-1.17)$ & $77.1 \%$ & $<0.001$ & \\
\hline Interview & 24 & 34.52 & $1.32(1.17-1.49)$ & $66.3 \%$ & $<0.001$ & \\
\hline Database & 6 & 9.06 & $1.00(0.85-1.18)$ & $77.1 \%$ & 0.004 & \\
\hline Number of adjusted variables & & & & & & 0.926 \\
\hline$\leq 4$ & 15 & 22.84 & $1.13(0.99-1.28)$ & $82.7 \%$ & $<0.001$ & \\
\hline$>4$ & 43 & 77.16 & $1.16(1.08-1.24)$ & $72.8 \%$ & $<0.001$ & \\
\hline Study score & & & & & & 0.585 \\
\hline Low quality & 17 & 25.20 & $1.16(0.98-1.37)$ & $86.9 \%$ & $<0.001$ & \\
\hline High quality & 41 & 74.80 & $1.14(1.08-1.21)$ & $61.6 \%$ & $<0.001$ & \\
\hline
\end{tabular}

${ }_{\mathrm{a}, \mathrm{b}}$ Five studies report their studies including different kinds of cancer; nine articles report their studies including different types of shift schedules. ${ }^{*} P$ values for metaregression.

on other cancers than on breast and prostate cancers, the low heterogeneity for digestive system cancer $(P=0.081$, $\left.I^{2}=40.2 \%\right)$, hematological system cancer $\left(P=0.066, I^{2}=\right.$ $54.7 \%)$, and lung cancer $\left(P=0.078, I^{2}=49.5 \%\right)$ presented a more reliable conclusion. Previous studies have suggested that a common mechanism might be shared among hormone-dependent cancers including prostate cancer in men and breast and ovarian cancers in women [91, 92]. Melatonin has been implicated in antiproliferation effects in vivo and in vitro, and an elevated PSA level has been strongly connected with night shift work [91, 93], which could illustrate why breast and prostate cancers are more sensitive to night shift work than other common cancers.
One meta-analysis [8] analyzing the influence of night shift work on the risk of multiple cancers in women included up to 61 articles. Although light at night (LAN) [94] has been considered one of the risk factors for cancer, studies describing LAN were not included in our meta-analysis if the analysis of LAN was not connected to night shift work. We also excluded cross-sectional studies or studies only describing sleep duration. Therefore, the exposure of all 58 studies in our article was night shift work, which could decrease the clinical heterogeneity, making a more reliable result possible. Whereas the definition of night shift work differs largely among studies, we further divided work schedules into fixed shift, rotating shift, and mixed schedule, to reduce 


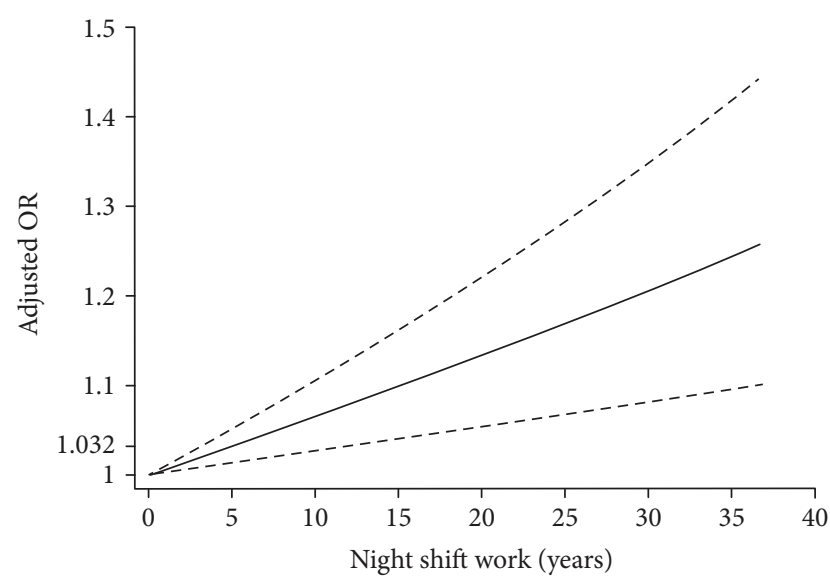

Figure 3: Dose-response relation plots between night shift work and the risk of multiple cancers. OR: odds ratio. Solid line represents the estimated OR by years, and the dotted lines represent the low and upper limits of $95 \%$ CIs separately.

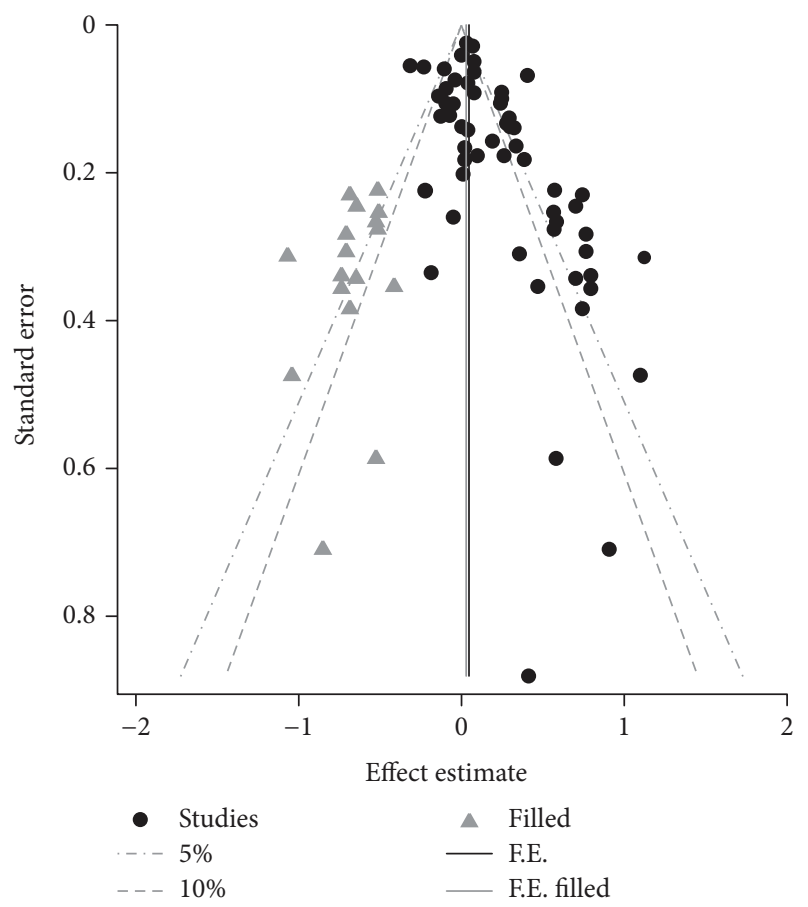

FIGURE 4: The contour-enhanced funnel plot of studies assessing the association between night shift work and the risk of cancers after using the trim and fill method.

heterogeneity. Consistent with Mancio et al. [79], rotating shift workers had evidence of a higher risk of cancer whereas no association was observed in fixed shift workers. One speculation was that constant and rapid changing work times among rotating shift workers may necessitate a severe circadian disruption, causing failed adaptation, whereas fixed night shift workers had sufficient time to adapt almost completely to the shift cycle [95]. Consequently, rotating shift work resulted in a more profound effect on carcinogenesis through severe circadian disruption.
Our subgroup analyses also uncovered other meaningful results. One finding demonstrated that prostate, breast, and digestive system cancers were connected with night shift work whereas night shift work did not raise the risk of cancers of the hematological system, reproductive system, lung, and skin. In addition, Yuan et al. [8] found that female night shift workers in Europe and North America have greater risk of cancer than women in Asia and Australia. Based on the whole population, our results were consistent with those findings and indicate that the association of cancer risk with night shift work is not largely different between men and women. The different associations might be attributed to the limitations of the study populations. Many studies from Asia were limited to industrial workers whereas most studies from Europe and North America were based on the general population. However, the contrasting results might essentially be owing to differences in ethnicity or sensitivity. More specific exploration based on ethnicity is indispensable in future research. Moreover, studies based on the general population showed a higher cancer risk than those among nurses and industrial workers, and the pooled ORs in population could be better generalized to the overall population. Cohort studies, meaning higher-quality study designs, also indicated the same positive association between night shift work and the risk of cancer. Accordingly, the higher pooled ORs in these subgroups could confirm this association more powerfully.

Through analyzing $Q$ and $I^{2}$ values, we found a significant heterogeneity among the studies included in this article $\left(P<0.001, I^{2}=76.2 \%\right)$; therefore, we used a random effects model to decrease the heterogeneity. After subgroup analyses, we found that fixed shift work, digestive system cancer, reproductive system cancer, unclassified occupation, interview data collection, and high-quality studies were related to less heterogeneity, representing more reliable results. However, all $P$ values in the metaregression analyses did not reflect a statistical difference, such that heterogeneity could not be explained by metaregression analysis. Oneby-one-omitted sensitivity and leave-one-out analyses showed that the pooled risk estimates were stable and positive, even when 19 studies were omitted, until heterogeneity was reduced to $29.8 \%$. Although we did not find an obvious source of heterogeneity, the specific subgroup analyses, such as a more uniform definition of work schedules, unclassified occupation based on population, more detailed interviews, and high-quality studies, could decrease the potential heterogeneity.

Theoretical biological mechanisms for the positive relationship between night shift work and cancer risk are complex. First, night shift work and LAN could disturb the normal synchrony with the day-night rhythm and sleeping and diet patterns and bring about circadian disruption, which could suppress the secretion of melatonin [80]. Melatonin plays a pivotal role in inhibiting carcinogenesis through antioxidation, regulation of the immune system, free radical scavenging, and antiangiogenesis [67]. Decreased melatonin levels might disturb its antiproliferation effects on prostate cancer cells both in vivo and in vitro [93] and induce continuous secretion of estrogen, to increase the risk 
of breast cancer [77]. Second, night shift work can reduce the exposure time to sunlight and subsequently decrease vitamin $\mathrm{D}$ levels [80]. Studies have supported the inverse association between circulating vitamin D levels and risk of breast [96], colorectal [97], and prostate cancer [98]. Third, from a molecular perspective, night shift work could constitute a disruption of the feedback loops of circadian genes and lead to subsequent disordered expression of transcription and translation in all cells, which could pose a threat to cell proliferation, metabolism, regulation of the immune system, and DNA damage repair, causing carcinogenesis $[73,74]$.

To the best of our knowledge, this meta-analysis is the first and most comprehensive of its kind to identify the association between night shift work and risk of cancer from the perspective of diverse cancers and by sex. There were several strengths in our meta-analysis. First, we enrolled a large number of articles, even using strict inclusion criteria. The massive study population could enhance statistical power and ensure more accurate risk estimation. Second, a linear dose-response analysis was used to quantify the association between accumulative years of night shift work and cancer risk. Third, we classified work schedules and found that rotating shift work could increase cancer risk whereas fixed shift work could not. The classification of work schedules could decrease clinical heterogeneity to make the results more reliable. Fourth, 34 of 57 studies were carried out among the general population, such that the pooled OR could be better extended to the entire population. Our meta-analysis also had several limitations. First, a significantly high heterogeneity was discovered. We observed significant variability in the study design, risk estimates, study population, definition of night shift work, and exposure assessment. Each of these aspects may generate heterogeneity. Even though many statistical methods were used, we still had trouble finding an obvious source of potential heterogeneity; therefore, the conclusions reached in our meta-analysis should be interpreted with caution. Second, the lack of a consistent definition of night shift work may lead to a certain degree of misclassification and result in a dilution of the pooled OR [8]. Third, given that most night shift workers tend to have lower socioeconomic status, a lower uptake of screening and response rates may result in underestimation of the pooled risk estimates. Finally, studies using interviews could actively collect more detailed information, presenting a stronger risk compared with studies using questionnaire- and database-based data collection. In addition, there is inherent recall bias when conducting interviews or questionnaires. Hence, different exposure assessment methods and studies with lower quality or a less number of adjusted variables can cause information bias.

In conclusion, our meta-analysis identified a positive relationship between night shift work and cancer risk, using a comprehensive perspective of common cancers. We revealed that the risk of cancer increases cumulatively by $3.2 \%$ for every 5 years of night shift work. Moreover, we found no difference between men and women in the association between night shift work and the risk of cancer. Overall, on the grounds that public health is adversely affected by night shift work and its prevalence is on the rise, it is indispensable to develop shift work schedules with the aim of reducing cancer risk. Our meta-analysis does not merely increase public awareness, it also supports the recommendation for regular cancer screening among night shift workers.

\section{Conflicts of Interest}

The authors declare no competing financial interests.

\section{Acknowledgments}

This study was partly funded by the National Natural Science Foundation of China (Grant Nos. NSFC 81502195 and NSFC 81672512) and Medicine and Health Science Technology Development Project of Shandong Province (No. 2016WS0258). We also thank Analisa Avila, ELS, of Liwen Bianji, Edanz Group China (http://www.liwenbianji. $\mathrm{cn} / \mathrm{ac}$ ), for editing the English text of a draft of this manuscript.

\section{Supplementary Materials}

Figure S1: forest plots of studies describing the association between night shift work and the risk of multiple cancers. $I^{2}$ : the indicator for judging the degree of heterogeneity; OR: odds ratio; CI: confidence interval. The squares and horizontal lines represent the study-specific OR and $95 \%$ CI. The diamond represents the pooled OR and 95\% CI. (Supplementary Materials)

\section{References}

[1] B. Aisbett, D. Condo, E. Zacharewicz, and S. Lamon, "The impact of shift work on skeletal muscle health," Nutrients, vol. 9, no. 3, 2017.

[2] K. P. Wright Jr., R. K. Bogan, and J. K. Wyatt, "Shift work and the assessment and management of shift work disorder (SWD)," Sleep Medicine Reviews, vol. 17, no. 1, pp. 41-54, 2013.

[3] D. B. Boivin, A. Shechter, P. Boudreau, E. A. Begum, and N. M. K. Ng Ying-Kin, "Diurnal and circadian variation of sleep and alertness in men vs. naturally cycling women," Proceedings of the National Academy of Sciences of the United States of America, vol. 113, no. 39, pp. 10980-10985, 2016.

[4] V. G. Vimalananda, J. R. Palmer, H. Gerlovin et al., "Nightshift work and incident diabetes among African-American women," Diabetologia, vol. 58, no. 4, pp. 699-706, 2015.

[5] B. Peplonska, A. Bukowska, and W. Sobala, "Association of rotating night shift work with BMI and abdominal obesity among nurses and midwives," PLoS One, vol. 10, no. 7, article e0133761, 2015.

[6] A. M. Pimenta, G. Kac, R. R. Campos e Souza, L. Maria de Barros Almeida Ferreira, and S. Maria de Fátima Silqueira, "Night-shift work and cardiovascular risk among employees of a public university," Revista Da Associacao Medica Brasileira, vol. 58, no. 2, pp. 168-177, 2012.

[7] D. A. Kalmbach, V. Pillai, P. Cheng, J. T. Arnedt, and C. L. Drake, "Shift work disorder, depression, and anxiety in the transition to rotating shifts: the role of sleep reactivity," Sleep Medicine, vol. 16, no. 12, pp. 1532-1538, 2015. 
[8] X. Yuan, C. Zhu, M. Wang, F. Mo, W. Du, and X. Ma, "Night shift work increases the risks of multiple primary cancers in women: a systematic review and meta-analysis of 61 articles," Cancer Epidemiology, Biomarkers \& Prevention, vol. 27, no. 1, pp. 25-40, 2018.

[9] K. Straif, R. Baan, Y. Grosse et al., "Carcinogenicity of shiftwork, painting, and fire-fighting," The Lancet Oncology, vol. 8, no. 12, pp. 1065-1066, 2007.

[10] L. R. Wegrzyn, R. M. Tamimi, B. A. Rosner et al., "Rotating night-shift work and the risk of breast cancer in the Nurses' Health Studies," American Journal of Epidemiology, vol. 186, no. 5, pp. 532-540, 2017.

[11] L. A. Tse, P. M. Y. Lee, W. M. Ho et al., "Bisphenol A and other environmental risk factors for prostate cancer in Hong Kong," Environment International, vol. 107, pp. 1-7, 2017.

[12] K. Papantoniou, G. Castaño Vinyals, A. Espinosa et al., "Shift work and colorectal cancer risk in the MCC-Spain casecontrol study," Scandinavian Journal of Work, Environment \& Health, vol. 43, no. 3, pp. 250-259, 2017.

[13] T. Behrens, S. Rabstein, K. Wichert et al., "Shift work and the incidence of prostate cancer: a 10-year follow-up of a German population-based cohort study," Scandinavian Journal of Work, Environment \& Health, vol. 43, no. 6, pp. 560-568, 2017.

[14] R. C. Travis, A. Balkwill, G. K. Fensom et al., "Night shift work and breast cancer incidence: three prospective studies and meta-analysis of published studies," Journal of the National Cancer Institute, vol. 108, no. 12, article djw169, 2016.

[15] L. Costas, Y. Benavente, R. Olmedo-Requena et al., "Night shift work and chronic lymphocytic leukemia in the MCC-Spain case-control study," International Journal of Cancer, vol. 139, no. 9, pp. 1994-2000, 2016.

[16] Y. Bai, X. Li, K. Wang et al., “Association of shift-work, daytime napping, and nighttime sleep with cancer incidence and cancer-caused mortality in Dongfeng-tongji cohort study," Annals of Medicine, vol. 48, no. 8, pp. 641-651, 2016.

[17] P. Wang, F. M. Ren, Y. Lin et al., "Night-shift work, sleep duration, daytime napping, and breast cancer risk," Sleep Medicine, vol. 16, no. 4, pp. 462-468, 2015.

[18] K. Papantoniou, G. Castaño-Vinyals, A. Espinosa et al., "Night shift work, chronotype and prostate cancer risk in the MCCSpain case-control study," International Journal of Cancer, vol. 137, no. 5, pp. 1147-1157, 2015.

[19] G. P. Hammer, K. Emrich, M. Nasterlack, M. Blettner, and M. Yong, "Shift work and prostate cancer incidence in industrial workers: a historical cohort study in a German chemical company," Deutsches Aerzteblatt Online, vol. 112, no. 27-28, pp. 463-470, 2015.

[20] F. Gu, J. Han, F. Laden et al., "Total and cause-specific mortality of U.S. nurses working rotating night shifts," American Journal of Preventive Medicine, vol. 48, no. 3, pp. 241-252, 2015.

[21] T. Akerstedt, A. Knutsson, J. Narusyte, P. Svedberg, G. Kecklund, and K. Alexanderson, "Night work and breast cancer in women: a Swedish cohort study," BMJ Open, vol. 5, no. 4, article e008127, 2015.

[22] T. Truong, B. Liquet, F. Menegaux et al., "Breast cancer risk, nightwork, and circadian clock gene polymorphisms," Endocrine-Related Cancer, vol. 21, no. 4, pp. 629-638, 2014.

[23] B. D. Carter, W. Ryan Diver, J. S. Hildebrand, A. V. Patel, and S. M. Gapstur, "Circadian disruption and fatal ovarian cancer,"
American Journal of Preventive Medicine, vol. 46, no. 3, pp. S34-S41, 2014.

[24] E. S. Schernhammer, D. Feskanich, G. Liang, and J. Han, "Rotating night-shift work and lung cancer risk among female nurses in the United States," American Journal of Epidemiology, vol. 178, no. 9, pp. 1434-1441, 2013.

[25] F. Menegaux, T. Truong, A. Anger et al., "Night work and breast cancer: a population-based case-control study in France (the CECILE study)," International Journal of Cancer, vol. 132, no. 4, pp. 924-931, 2013.

[26] A. Knutsson, L. Alfredsson, B. Karlsson et al., "Breast cancer among shift workers: results of the WOLF longitudinal cohort study," Scandinavian Journal of Work, Environment \& Health, vol. 39, no. 2, pp. 170-177, 2013.

[27] A. Grundy, H. Richardson, I. Burstyn et al., "Increased risk of breast cancer associated with long-term shift work in Canada," Occupational and Environmental Medicine, vol. 70, no. 12, pp. 831-838, 2013.

[28] M. E. Parent, M. El-Zein, M. C. Rousseau, J. Pintos, and J. Siemiatycki, "Night work and the risk of cancer among men," American Journal of Epidemiology, vol. 176, no. 9, pp. 751-759, 2012.

[29] J. Natti, T. Anttila, T. Oinas, and A. Mustosmaki, "Night work and mortality: prospective study among Finnish employees over the time span 1984 to 2008," Chronobiology International, vol. 29, no. 5, pp. 601-609, 2012.

[30] J. Hansen and R. G. Stevens, "Case-control study of shift-work and breast cancer risk in Danish nurses: impact of shift systems," European Journal of Cancer, vol. 48, no. 11, pp. 1722-1729, 2012.

[31] J. Hansen and C. F. Lassen, "Nested case-control study of night shift work and breast cancer risk among women in the Danish military," Occupational and Environmental Medicine, vol. 69, no. 8, pp. 551-556, 2012.

[32] T. Kubo, I. Oyama, T. Nakamura et al., "Industry-based retrospective cohort study of the risk of prostate cancer among rotating-shift workers," International Journal of Urology, vol. 18, no. 3, pp. 206-211, 2011.

[33] T. A. Lahti, T. Partonen, P. Kyyrönen, T. Kauppinen, and E. Pukkala, "Night-time work predisposes to non-Hodgkin lymphoma," International Journal of Cancer, vol. 123, no. 9, pp. 2148-2151, 2008.

[34] A. N. Viswanathan, S. E. Hankinson, and E. S. Schernhammer, "Night shift work and the risk of endometrial cancer," Cancer Research, vol. 67, no. 21, pp. 10618-10622, 2007.

[35] E. S. Schernhammer, C. H. Kroenke, F. Laden, and S. E. Hankinson, "Night work and risk of breast cancer," Epidemiology, vol. 17, no. 1, pp. 108-111, 2006.

[36] J. A. S. Lie, J. Roessink, and K. Kjærheim, "Breast cancer and night work among Norwegian nurses," Cancer Causes \& Control, vol. 17, no. 1, pp. 39-44, 2006.

[37] T. Kubo, K. Ozasa, K. Mikami et al., "Prospective cohort study of the risk of prostate cancer among rotating-shift workers: findings from the Japan collaborative cohort study," American Journal of Epidemiology, vol. 164, no. 6, pp. 549-555, 2006.

[38] E. S. Schernhammer, F. Laden, F. E. Speizer et al., "Night-shift work and risk of colorectal cancer in the Nurses' Health Study," Journal of the National Cancer Institute, vol. 95, no. 11, pp. 825-828, 2003. 
[39] J. Hansen, "Increased breast cancer risk among women who work predominantly at night," Epidemiology, vol. 12, no. 1, pp. 74-77, 2001.

[40] W. M. Walasa, R. N. Carey, S. Si et al., "Association between shiftwork and the risk of colorectal cancer in females: a population-based case-control study," Occupational and Environmental Medicine, vol. 75, no. 5, pp. 344-350, 2018.

[41] M. Talibov, E. Pukkala, J. I. Martinsen, L. Tryggvadottir, E. Weiderpass, and J. Hansen, "Night-shift work and hematological cancers: a population based case-control study in three Nordic countries," Scandinavian Journal of Work, Environment \& Health, vol. 44, no. 3, pp. 258-264, 2018.

[42] H. T. Vistisen, A. H. Garde, M. Frydenberg et al., "Short-term effects of night shift work on breast cancer risk: a cohort study of payroll data," Scandinavian Journal of Work, Environment \& Health, vol. 43, no. 1, pp. 59-67, 2017.

[43] J. T. Jørgensen, S. Karlsen, L. Stayner, J. Hansen, and Z. J. Andersen, "Shift work and overall and cause-specific mortality in the Danish nurse cohort," Scandinavian Journal of Work, Environment \& Health, vol. 43, no. 2, pp. 117-126, 2017.

[44] C. J. Heckman, J. D. Kloss, D. Feskanich, E. Culnan, and E. S. Schernhammer, "Associations among rotating night shift work, sleep and skin cancer in Nurses' Health Study II participants," Occupational and Environmental Medicine, vol. 74, no. 3, pp. 169-175, 2017.

[45] E. E. Devore, J. Massa, K. Papantoniou et al., "Rotating night shift work, sleep, and colorectal adenoma in women," International Journal of Colorectal Disease, vol. 32, no. 7, pp. 1013-1018, 2017.

[46] T. Akerstedt, J. Narusyte, P. Svedberg, G. Kecklund, and K. Alexanderson, "Night work and prostate cancer in men: a Swedish prospective cohort study," BMJ Open, vol. 7, no. 6, article e015751, 2017.

[47] K. Papantoniou, G. Castaño-Vinyals, A. Espinosa et al., "Breast cancer risk and night shift work in a case-control study in a Spanish population," European Journal of Epidemiology, vol. 31, no. 9, pp. 867-878, 2016.

[48] G. Gyarmati, M. C. Turner, G. Castaño-Vinyals et al., "Night shift work and stomach cancer risk in the MCC-Spain study," Occupational and Environmental Medicine, vol. 73, no. 8, pp. 520-527, 2016.

[49] B. A. Dickerman, S. C. Markt, M. Koskenvuo et al., "Sleep disruption, chronotype, shift work, and prostate cancer risk and mortality: a 30-year prospective cohort study of Finnish twins," Cancer Causes \& Control, vol. 27, no. 11, pp. 13611370, 2016.

[50] Y. Lin, T. Nishiyama, M. Kurosawa et al., "Association between shift work and the risk of death from biliary tract cancer in Japanese men," BMC Cancer, vol. 15, no. 1, p. 757, 2015.

[51] W. Li, R. M. Ray, D. B. Thomas et al., "Shift work and breast cancer among women textile workers in Shanghai, China," Cancer Causes \& Control, vol. 26, no. 1, pp. 143-150, 2015.

[52] P. Kwon, J. Lundin, W. Li et al., "Night shift work and lung cancer risk among female textile workers in Shanghai, China," Journal of Occupational and Environmental Hygiene, vol. 12, no. 5, pp. 334-341, 2015.

[53] M. Yong, M. Blettner, K. Emrich, M. Nasterlack, C. Oberlinner, and G. P. Hammer, "A retrospective cohort study of shift work and risk of incident cancer among German male chemical workers," Scandinavian Journal of Work, Environment \& Health, vol. 40, no. 5, pp. 502-510, 2014.
[54] L. L. J. Koppes, G. A. Geuskens, A. Pronk, R. C. H. Vermeulen, and E. M. M. de Vroome, "Night work and breast cancer risk in a general population prospective cohort study in the Netherlands," European Journal of Epidemiology, vol. 29, no. 8, pp. 577-584, 2014.

[55] S. M. Gapstur, W. R. Diver, V. L. Stevens, B. D. Carter, L. R. Teras, and E. J. Jacobs, "Work schedule, sleep duration, insomnia, and risk of fatal prostate cancer," American Journal of Preventive Medicine, vol. 46, no. 3, pp. S26-S33, 2014.

[56] K. Datta, A. Roy, D. Nanda et al., "Association of breast cancer with sleep pattern-a pilot case control study in a regional cancer centre in South Asia," Asian Pacific Journal of Cancer Prevention, vol. 15, no. 20, pp. 8641-8645, 2014.

[57] S. Rabstein, V. Harth, B. Pesch et al., "Night work and breast cancer estrogen receptor status-results from the German GENICA study," Scandinavian Journal of Work, Environment \& Health, vol. 39, no. 5, pp. 448-455, 2013.

[58] Y. Lin, J. Ueda, K. Yagyu, M. Kurosawa, A. Tamakoshi, and S. Kikuchi, "A prospective cohort study of shift work and the risk of death from pancreatic cancer in Japanese men," Cancer Causes \& Control, vol. 24, no. 7, pp. 1357-1361, 2013.

[59] L. Fritschi, T. C. Erren, D. C. Glass et al., "The association between different night shiftwork factors and breast cancer: a case-control study," British Journal of Cancer, vol. 109, no. 9, pp. 2472-2480, 2013.

[60] P. Bhatti, K. L. Cushing-Haugen, K. G. Wicklund, J. A. Doherty, and M. A. Rossing, "Nightshift work and risk of ovarian cancer," Occupational and Environmental Medicine, vol. 70, no. 4, pp. 231-237, 2013.

[61] E. M. Poole, E. S. Schernhammer, and S. S. Tworoger, "Rotating night shift work and risk of ovarian cancer," Cancer Epidemiology, Biomarkers \& Prevention, vol. 20, no. 5, pp. 934-938, 2011.

[62] J. A. S. Lie, H. Kjuus, S. Zienolddiny, A. Haugen, R. G. Stevens, and K. Kjaerheim, "Night work and breast cancer risk among Norwegian nurses: assessment by different exposure metrics," American Journal of Epidemiology, vol. 173, no. 11, pp. 1272-1279, 2011.

[63] A. Pronk, B. T. Ji, X. O. Shu et al., "Night-shift work and breast cancer risk in a cohort of Chinese women," American Journal of Epidemiology, vol. 171, no. 9, pp. 953-959, 2010.

[64] B. Pesch, V. Harth, S. Rabstein et al., "Night work and breast cancer-results from the German GENICA study," Scandinavian Journal of Work, Environment \& Health, vol. 36, no. 2, pp. 134-141, 2010.

[65] E. S. O'Leary, E. R. Schoenfeld, R. G. Stevens et al., "Shift work, light at night, and breast cancer on Long Island, New York," American Journal of Epidemiology, vol. 164, no. 4, pp. 358366, 2006.

[66] S. Davis, D. K. Mirick, and R. G. Stevens, "Night shift work, light at night, and risk of breast cancer," Journal of the National Cancer Institute, vol. 93, no. 20, pp. 1557-1562, 2001.

[67] M. Zhao, J. Wan, K. Zeng et al., "The reduction in circulating melatonin level may contribute to the pathogenesis of ovarian cancer: a retrospective study," Journal of Cancer, vol. 7, no. 7, pp. 831-836, 2016.

[68] D. K. Mirick, P. Bhatti, C. Chen, F. Nordt, F. Z. Stanczyk, and S. Davis, "Night shift work and levels of 6-sulfatoxymelatonin and cortisol in men," Cancer Epidemiology, Biomarkers \& Prevention, vol. 22, no. 6, pp. 1079-1087, 2013. 
[69] S. Davis, D. K. Mirick, C. Chen, and F. Z. Stanczyk, "Night shift work and hormone levels in women," Cancer Epidemiology, Biomarkers \& Prevention, vol. 21, no. 4, pp. 609-618, 2012.

[70] A. Rodriguez-Garcia, J. C. Mayo, D. Hevia, I. QuirosGonzalez, M. Navarro, and R. M. Sainz, "Phenotypic changes caused by melatonin increased sensitivity of prostate cancer cells to cytokine-induced apoptosis," Journal of Pineal Research, vol. 54, no. 1, pp. 33-45, 2013.

[71] P. Lissoni, M. Chilelli, S. Villa, L. Cerizza, and G. Tancini, "Five years survival in metastatic non-small cell lung cancer patients treated with chemotherapy alone or chemotherapy and melatonin: a randomized trial," Journal of Pineal Research, vol. 35, no. 1, pp. 12-15, 2003.

[72] C. Persson, B. Glimelius, J. Ronnelid, and P. Nygren, "Impact of fish oil and melatonin on cachexia in patients with advanced gastrointestinal cancer: a randomized pilot study," Nutrition, vol. 21, no. 2, pp. 170-178, 2005.

[73] L. Kervezee, M. Cuesta, N. Cermakian, and D. B. Boivin, "Simulated night shift work induces circadian misalignment of the human peripheral blood mononuclear cell transcriptome," Proceedings of the National Academy of Sciences of the United States of America, vol. 115, no. 21, pp. 5540-5545, 2018.

[74] N. M. Kettner, C. A. Katchy, and L. Fu, "Circadian gene variants in cancer," Annals of Medicine, vol. 46, no. 4, pp. 208-220, 2014.

[75] H. E. Lee, J. Lee, T. W. Jang, I. A. Kim, J. Park, and J. Song, "The relationship between night work and breast cancer," Annals of Occupational and Environmental Medicine, vol. 30, no. 1, p. 11, 2018.

[76] C. He, S. T. Anand, M. H. Ebell, J. E. Vena, and S. W. Robb, "Circadian disrupting exposures and breast cancer risk: a meta-analysis," International Archives of Occupational and Environmental Health, vol. 88, no. 5, pp. 533-547, 2015.

[77] F. Wang, K. L. Yeung, W. C. Chan et al., "A meta-analysis on dose-response relationship between night shift work and the risk of breast cancer," Annals of Oncology, vol. 24, no. 11, pp. 2724-2732, 2013.

[78] B. B. Kamdar, A. I. Tergas, F. J. Mateen, N. H. Bhayani, and J. Oh, "Night-shift work and risk of breast cancer: a systematic review and meta-analysis," Breast Cancer Research and Treatment, vol. 138, no. 1, pp. 291-301, 2013.

[79] J. Mancio, C. Leal, M. Ferreira, P. Norton, and N. Lunet, “Does the association of prostate cancer with night-shift work differ according to rotating vs. fixed schedule? A systematic review and meta-analysis," Prostate Cancer and Prostatic Diseases, vol. 21, no. 3, pp. 337-344, 2018.

[80] Y. Gan, L. Li, L. Zhang et al., “Association between shift work and risk of prostate cancer: a systematic review and metaanalysis of observational studies," Carcinogenesis, vol. 39, no. 2, pp. 87-97, 2018.

[81] H. B. Du, K. Y. Bin, W. H. Liu, and F. S. Yang, "Shift work, night work, and the risk of prostate cancer: a meta-analysis based on 9 cohort studies," Medicine, vol. 96, no. 46, article e8537, 2017.

[82] X. Wang, A. Ji, Y. Zhu et al., "A meta-analysis including doseresponse relationship between night shift work and the risk of colorectal cancer," Oncotarget, vol. 6, no. 28, pp. 25046-25060, 2015.

[83] L. Yan and R. Silver, "Neuroendocrine underpinnings of sex differences in circadian timing systems," The Journal of Steroid
Biochemistry and Molecular Biology, vol. 160, pp. 118-126, 2016.

[84] F. P. M. Kruijver and D. F. Swaab, "Sex hormone receptors are present in the human suprachiasmatic nucleus," Neuroendocrinology, vol. 75, no. 5, pp. 296-305, 2002.

[85] S. W. Cain, C. F. Dennison, J. M. Zeitzer et al., "Sex differences in phase angle of entrainment and melatonin amplitude in humans," Journal of Biological Rhythms, vol. 25, no. 4, pp. 288-296, 2010.

[86] N. Santhi, A. S. Lazar, P. J. McCabe, J. C. Lo, J. A. Groeger, and D. J. Dijk, "Sex differences in the circadian regulation of sleep and waking cognition in humans," Proceedings of the National Academy of Sciences of the United States of America, vol. 113, no. 19, pp. E2730-E2739, 2016.

[87] F. H. Rangtell, S. Karamchedu, P. Andersson et al., "A single night of sleep loss impairs objective but not subjective working memory performance in a sex-dependent manner," Journal of Sleep Research, 2018.

[88] S. Greenland, "Quantitative methods in the review of epidemiologic literature," Epidemiologic Reviews, vol. 9, no. 1, pp. 1-30, 1987.

[89] G. A. Wells, B. Shea, D. O'Connell et al., The NewcastleOttawa Scale (NOS) for Assessing the Quality of Nonrandomised Studies in Meta-analyses, Ottawa Hospital Research Institute, 2014.

[90] B. C. Wallace, C. H. Schmid, J. Lau, and T. A. Trikalinos, "Meta-analyst: software for meta-analysis of binary, continuous and diagnostic data," BMC Medical Research Methodology, vol. 9, no. 1, 2009.

[91] E. E. Flynn-Evans, L. Mucci, R. G. Stevens, and S. W. Lockley, "Shiftwork and prostate-specific antigen in the National Health and Nutrition Examination Survey," Journal of the National Cancer Institute, vol. 105, no. 17, pp. 1292-1297, 2013.

[92] Y. Zhu, T. Zheng, R. G. Stevens, Y. Zhang, and P. Boyle, "Does "clock" matter in prostate cancer?," Cancer Epidemiology, Biomarkers \& Prevention, vol. 15, no. 1, pp. 3-5, 2006.

[93] B. Jung-Hynes, T. L. Schmit, S. R. Reagan-Shaw, I. A. Siddiqui, H. Mukhtar, and N. Ahmad, "Melatonin, a novel Sirt 1 inhibitor, imparts antiproliferative effects against prostate cancer in vitro in culture and in vivo in TRAMP model," Journal of Pineal Research, vol. 50, no. 2, pp. 140-149, 2011.

[94] C. M. Hunter and M. G. Figueiro, "Measuring light at night and melatonin levels in shift workers: a review of the literature," Biological Research for Nursing, vol. 19, no. 4, pp. 365-374, 2017.

[95] C. Williams, "Work-life balance of shift workers," Perspectives on Labour \& Income, vol. 9, pp. 5-16, 2008.

[96] J. Obaidi, E. Musallam, H. M. Al-Ghzawi, S. N. Azzeghaiby, and I. N. Alzoghaibi, "Vitamin D and its relationship with breast cancer: an evidence based practice paper," Global Journal of Health Science, vol. 7, no. 1, pp. 261-266, 2014.

[97] E. Giovannucci, "Epidemiology of vitamin D and colorectal cancer," Anti-Cancer Agents in Medicinal Chemistry, vol. 13, no. 1, pp. 11-19, 2013.

[98] G. G. Schwartz, "Vitamin D, sunlight, and the epidemiology of prostate cancer," Anti-Cancer Agents in Medicinal Chemistry, vol. 13, no. 1, pp. 45-57, 2013. 


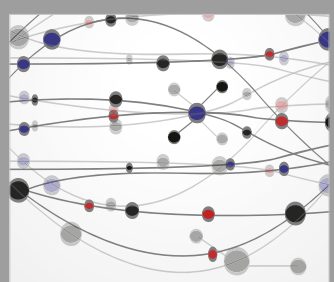

The Scientific World Journal
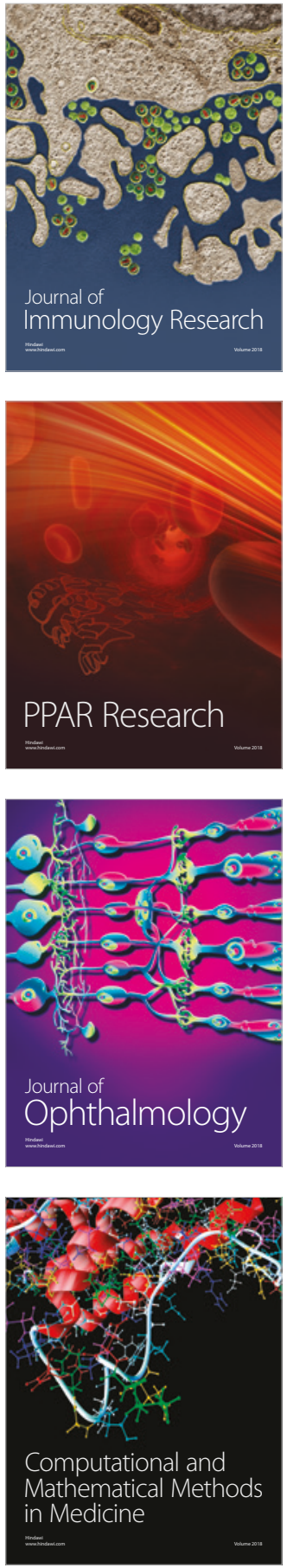

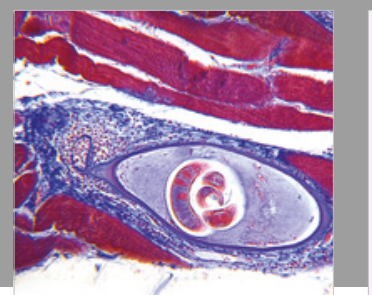

Gastroenterology Research and Practice

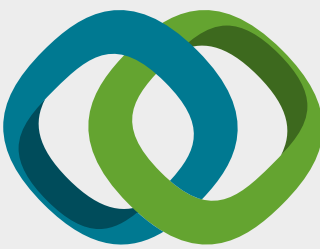

\section{Hindawi}

Submit your manuscripts at

www.hindawi.com
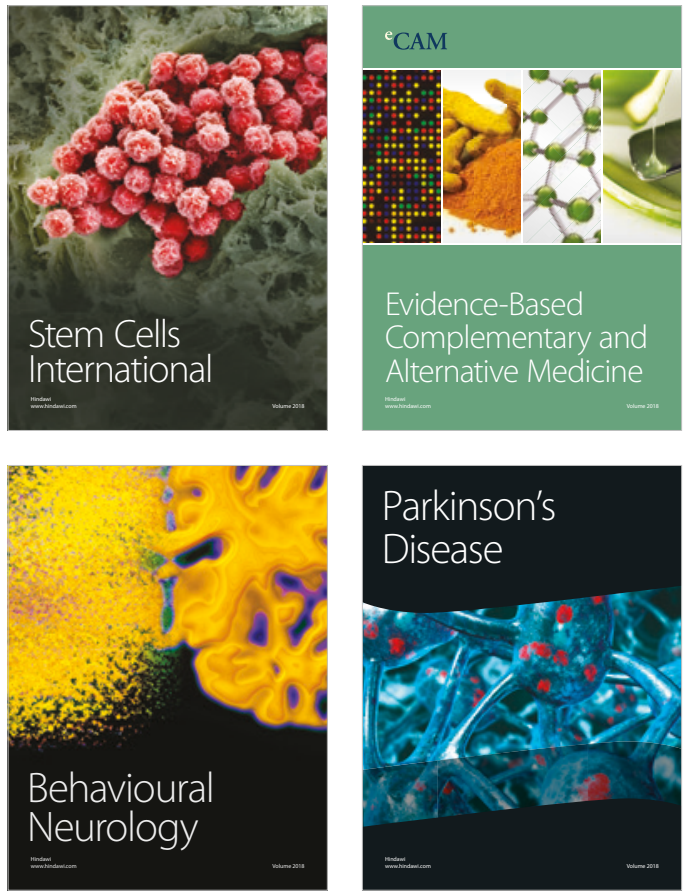

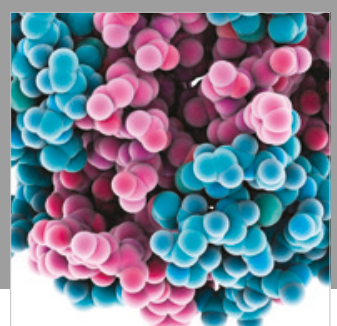

ournal of

Diabetes Research

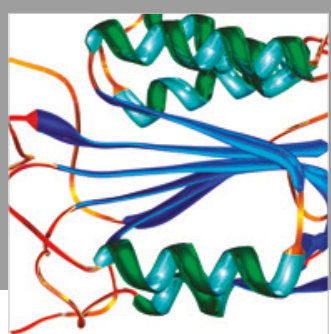

Disease Markers
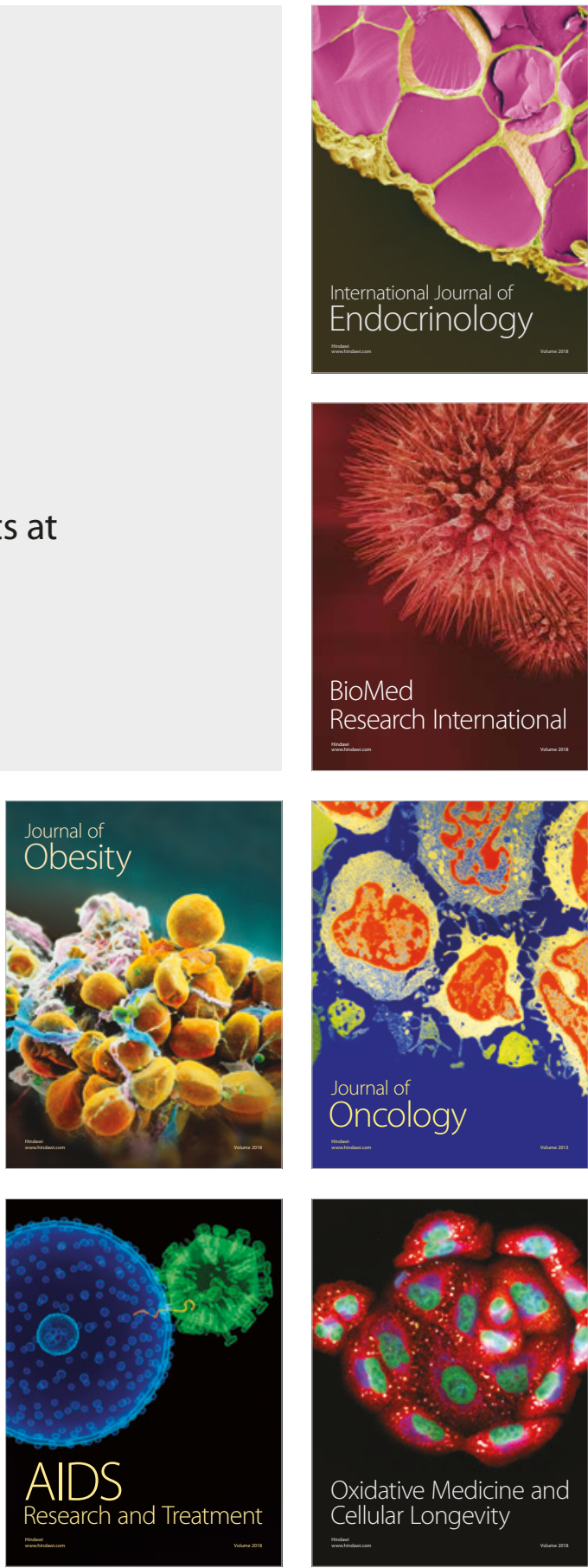